Int. J. Dev. Biol. 49: 781-796 (2005)

doi: $10.1387 / \mathrm{ijdb} .052003 \mathrm{ep}$

Original Article

\title{
Exploration of the extracellular space by a large-scale secretion screen in the early Xenopus embryo
}

\author{
EDGAR M. PERA*,1,2, SHIRUI HOU ${ }^{2}$, INA STRATE ${ }^{2}$, OLIVER WESSELY1,3 and EDWARD M. DE ROBERTIS ${ }^{1}$ \\ ${ }^{1}$ Howard Hughes Medical Institute and Department of Biological Chemistry, University of California, Los Angeles, USA, ${ }^{2}$ Institut für \\ Biochemie und Molekulare Zellbiologie, Abteilung Entwicklungsbiochemie, Georg-August-Universität Göttingen, Göttingen, Germany and \\ ${ }^{3}$ LSU Health Sciences Center, Departments of Cell Biology \& Anatomy and Genetics, New Orleans, USA
}

\begin{abstract}
Secreted proteins play a crucial role in intercellular communication during embryogenesis and in the adult. We recently described a novel method, designated as secretion cloning, that allows identifying extracellular proteins exclusively based on their ability to be secreted by transfected cells. In this paper, we present the results of a large-scale screening of more than 90,000 clones from three cDNA expression libraries constructed from early Xenopus embryos. Of 170 sequenced clones, 65 appeared to encode secreted proteins; 26 clones $(40 \%)$ were identical to previously known Xenopus genes, 25 clones (38\%) were homologous to other genes identified in various organisms and 14 clones (22\%) were novel. Apart from these bona fide secreted proteins, we also isolated lysosomal or other secretory pathway proteins and some cytoplasmic proteins commonly found in body fluids. Among the novel secreted proteins were two putative growth factors of the Granulin family, termed xGra1 and xGra2; they are structurally similar to EGF and TGF $\alpha$ and show a spotted expression pattern in the epidermis. Another secreted protein, designated xSOUL, belongs to the family of heme-binding proteins and exhibits distinct expression in the early brain. A third protein, termed Xystatin, is related to cysteine proteinase inhibitors. Our results indicate that secretion cloning is an effective and generally useful tool for the unbiased isolation of secreted proteins.
\end{abstract}

KEY WORDS: secretion cloning, maternal, gastrula, Spemann-Mangold organizer, lysosomal

\section{Introduction}

A major challenge in developmental biology is to explore the molecular mechanisms that underly cell-cell interactions. The importance of intercellular signaling has long been appreciated in inductive processes, in which one tissue emits signals that change the fate of its neighbors. A classic example is the SpemannMangold organizer, a region of the amphibian gastrula, which is a source of signals that induce the central nervous system and pattern the early embryo (Spemann and Mangold, 1924). More recently, key roles for extracellular signaling have been recognized in important biological processes such as growth, differentiation and cancer progression. Studies in Xenopus have provided much insight into our understanding of cell-cell signaling. Secreted proteins and their cell surface receptors regulate many developmental processes. For example, members of the bone morphogenetic protein (BMP), Activin, Hedgehog and Wnt family, along with fibroblast growth factor (FGF) and Notch proteins, are critical for patterning and morphogenesis. The normal function of tissue requires elaborate mechanisms for the cells to send signals and exchange information. Extracellular proteins may bind to the ligands or receptors and serve as positive or negative modulators. These are frequently subject to proteolytic cleavage by enzymes, which in turn may be blocked by protease inhibitors. Thus, different layers of regulation exist that modulate growth factor signaling in the extracellular space (reviewed in De Robertis and Kuroda, 2004). Because of the important developmental roles of secreted proteins, particular efforts have been made to identify genes encoding such proteins. A common feature of extracellular proteins that can be used for their isolation is the presence of a

Abbreviations used in this paper: BLAST, basic local alignment search tool; BMP, bone morphogenetic protein; EGF, epidermal growth factor; ER, endoplasmic reticulum; EST, expressed sequence tag; FGF, fibroblast growth factor; IGF, insulin-like growth factor; kD, kilo Dalton; LiCl, lithium chloride; NCBI, national center for biotechnology information; S, sulfur; SDS-PAGE, sodium dodecylsulphate polyacrylamide gel electrophoresis; TGF, transforming growth factor; UV, ultraviolet light; xGra, Xenopus Granulin.

\footnotetext{
*Address correspondence to: Dr. Edgar M. Pera. Lund Stem Cell Center, BMC, B13, Klinikgatan 26, S-22184 Lund, Sweden. Fax +46-46-222-0899. e-mail: edgar.pera@med.lu.se
} 
Fig. 1. Secretion Cloning: a novel approach to isolate secreted proteins. (A) Overview of the method. Bacterial colonies from expression cDNA libraries are picked from agar plates and individually grown in 96 well blocks. Culture media from 16 clones are pooled and plasmid DNA prepared by miniprep. Human embryonic kidney 293T cells are co-transfected with the cDNA pools and pAdvantage (pAdv) DNA. After 36 hours, the transfected cells are labeled with ${ }^{35} \mathrm{~S}$-Methionine ${ }^{35} \mathrm{~S}-\mathrm{Cys}$ teine and incubated for another 36 hours. Proteins in the cell supernatant are separated by SDS-PAGE and detected byautoradiography. Once a candidate pool is identified, the procedure is repeated using subpools to individualize the positive cDNA clone. (B) Method of sib-selection. Left panel, bacteria from selected pools were regrown in a 96 well block and the 16 clones of each pool arrayed in $4 \times 4$ wells. The molecular weight of the candidate protein in each pool is indicated on the side. Note that pools grouped next to each other should differ in their molecular weight. Right panel, autoradiogram of protein gels. Each lane is loaded with the supernatant of cells transfected with a subpool of eight cDNA clones, prepared from one column (letter) or one row (number) of the 96 well block. Note that a positive clone is identified, when the bands in two lanes have the same molecular weight as the original pool. (C) Example of an SDS-PAGE of radioactive supernatants of 293T cells transfected with pools of 16 cDNA clones from a Xenopus gastrula library. Note in lanes 12 and 14 bands of 34 and $45 \mathrm{kD}$, respectively, which led to the initial identification of secreted Frizzled-related Protein-2 (sFRP2) and Protease inhibitor Nexin-1 (PN-1) in Xenopus. (D) Optimization of transfection conditions; cDNA clones encoding Protein Phosphatase X (PPX) or Xenopus Cystatin (xCys) were transfected alone (lanes 1-3) or with $10 \%$ pAdvantage DNA (pAdv, lanes 4-6). The time between transfection and the addition of ${ }^{35} S$-methionine ${ }^{35} S$-cysteine is indicated in hours. Note that the protein yield is highest in the presence of pAdvantage and when metabolic labeling was started 36 hours after transfection. (E) Detection of Sizzled, PPX and XCys protein in the medium of transfected cells after varying lengths of radioactive labeling. Note that conditioning for 36 hours yields strong signals of the desired proteins, while longer incubation increases non-specific background.

signal peptide, i.e. a cleavable sequence of 15-30 mainly hydrophobic amino acids at the amino-terminus, which confers passage of the protein into the secretory pathway (Bendtsen et al., 2004). Although there is little sequence conservation among signal peptides, their uniformity of function can be exploited in a gene isolation strategy termed signal sequence trap. cDNAs encoding signal peptides can redirect the expression of an exportdefective receptor to the surface of mammalian cultured cells (Tashiro etal., 1999). Alternatively, cDNAs encoding extracellular proteins can be selected based upon their ability to provide a functional signal peptide to a truncated enzyme in yeast (Klein et al., 1996). In mice, reporter gene insertions into genes encoding secreted proteins (,secretory traps") have been identified in embryonic stem cells based on membrane insertion of $\beta$-Gal fusions with "trapped“ signal peptides (Skarnes et al., 1995). However, these approaches are not exclusively directed against secreted proteins, but they also target transmembrane proteins or proteins localized to the endoplasmic reticulum, Golgi apparatus and lysosomes. Importantly, the isolated cDNA clones are only partial and additional effort needs to be subsequently made in each case to isolate full-length cDNAs for functional studies. We have reported a novel method, termed secretion cloning, to directly isolate full-length cDNA clones encoding secreted proteins (Pera and De Robertis, 2000). Secreted proteins were identified by monitoring the supernatant of human 293T cells transfected with small pools of cDNA clones from Xenopus expression cDNA libraries. Following metabolic labeling with ${ }^{35} \mathrm{~S}$ methionine and ${ }^{35} \mathrm{~S}$-cysteine, proteins released into the culture medium were separated by gel electrophoresis and detected by autoradiography. This unbiased method allowed the isolation of secreted proteins as full-length cDNA clones that could be directly used for functional characterization in mRNA microinjection experiments. Using this method, we have so far reported on the isolation of four soluble Wnt antagonists of the secreted Frizzledrelated protein family, namely Frzb-1, Sizzled, sFRP-2 and Crescent, which exhibit distinct activities in early head development (Pera and De Robertis, 2000). We also isolated the Nodal antagonist Antivin and this construct contributed to the realization that neural induction occurs in the absence of mesoderm (Wessely et al., 2001). Another secreted protein, termed IGFBP5, led us to describe a new role for insulin-like growth factor (IGF) signaling in head and neural induction (Pera et al., 2001). In addition, we 
presented three novel secreted proteins, including Isthmin as a new member of the FGF synexpression group (Pera et al., 2002) and two members of the glutamate carboxypeptidase family, designated as Darmin and Darmin-related (Pera et al., 2003). Despite these individual reports on some isolates, this comprehensive screen has never been published as a whole. Here we summarize our results and provide a complete overview of screening 91,376 clones from three different Xenopus cDNA libraries. We present 87 new ESTs and three full-length cDNA sequences of secreted proteins and other components of the secretory pathway. In addition, some cytoplasmic and nuclear proteins were retrieved in our screen of ${ }^{35} \mathrm{~S}$-labelled proteins. Furthermore, we present here the expression patterns of six selected genes encoding secretory proteins. Our results demonstrate that secretion cloning is well suited to explore the molecular composition of the extracellular space and to identify novel secreted proteins.

\section{Results}

\section{Strategy of secretion cloning}

To explore the molecular composition of the extracellular space, we performed an unbiased screen for proteins secreted in the early Xenopus embryo (Pera and De Robertis, 2000). We developed a novel method that allows one to directly isolate fulllength cDNA clones encoding secreted proteins (Fig. 1; for details, see Materials and Methods). Human 293T cells were transfected with small pools of cDNA clones from Xenopus expression libraries and newly synthesized proteins were radioactively labeled with ${ }^{35}$ S-Methionine and ${ }^{35}$ S-Cysteine (Fig. 1A). Proteins secreted into the supernatant were detected by SDSPAGE and autoradiography. Positive clones were individualized in a second step using sib selection (Fig. 1B) and partially sequenced from the 5 ' end to reveal their identity. One important criterion in the course of the screen was that many secreted proteins undergo glycosylation, while passing the ER and the Golgi apparatus. Hence secreted proteins generate a diffuse smear (rather than distinct band) when separated by gel electrophoresis (Fig. 1C). In order to improve the secretion of proteins, we transfected cDNA clones previously isolated by secretion cloning and examined different culture conditions. The pAdvantage plasmid (Promega) encodes the adenoviral Virus Associated I (VAI) RNA, which increases transient protein expression in vari-

Fig. 2. Overview of the proteins isolated by secretion cloning. (A) Positive clones identified in three expression CDNA libraries from early Xenopus embryos. The number on top of each bar indicates the number of proteins isolated as bands by SDS-PAGE in the supernatant of transfected cells. The black portion of the bars indicates unique sequences. (B) Number of known proteins that have functionally been characterized in Xenopus, related proteins characterized in other vertebrates but not in Xenopus and novel proteins not characterized yet. (C) Unique sequences isolated in the individual expression cDNA libraries. (D) Predicted subcellular localization of CDNAs related to those of other species or to known Xenopus cDNAs. Proteins are subdivided into secreted, lysosomal/ endoplasmatic reticulum (ER)/Golgi apparatus and cytoplasmatic/nuclear; numbers of cDNAs identified are indicated. (E) Subcellular localization of known and related sequences in each cDNA library. $M$, maternal library (32cell stage); $v G$, ventral gastrula stage library, $d G$, dorsal gastrula stage library. ous cell lines probably by stimulating translation initiation; VAI RNA is thought to relieve suppression of the translation initiation factor elF-2 by the double-strand RNA-activated inhibitor (DAI) that is activated by transfection. Co-transfection of cDNA with pAdvantage into 293T cells significantly enhanced the protein yield as shown in Figure 1D (compare lanes 4-6 with 1-3). The strongest signal was obtained, when the transfected cells were incubated for 36 hours before the onset of metabolic labeling. Longer incubation reduced protein biosynthesis, perhaps because cells reached confluence and exited the cell cycle. We further investigated the optimal length of metabolic labeling (Fig. $1 \mathrm{E})$. After addition of ${ }^{35} \mathrm{~S}-M e t h i o n i n e ~ a n d{ }^{35} \mathrm{~S}-\mathrm{Cysteine}$, proteins synthesized from the transfected cDNA were best detected after 36 hours (Fig. 1E; lanes 1-3). Harvesting the supernatant at a later time point was disadvantageous, since background accumulated due to the release of non-specific proteins from lysing cells (Fig. $1 \mathrm{E}$; lane 4).

\section{Spectrum of secreted proteins}

In total, we sceened 91,376 clones from three different expression cDNA libraries (Fig. 2A). One library was prepared from 32-cell stage embryos representing maternally expressed $\mathrm{mR}$ NAs. The source of the two other libraries were gastrula embryos that have been partially ventralized by UV light exposure or dorsalized by lithium chloride ( $\mathrm{LiCl}$ ) treatment, respectively. We isolated 170 cDNA clones that showed radioactively labeled bands in several independent transfection experiments, partially sequenced them from the 5' end and analyzed them by BLAST to

A
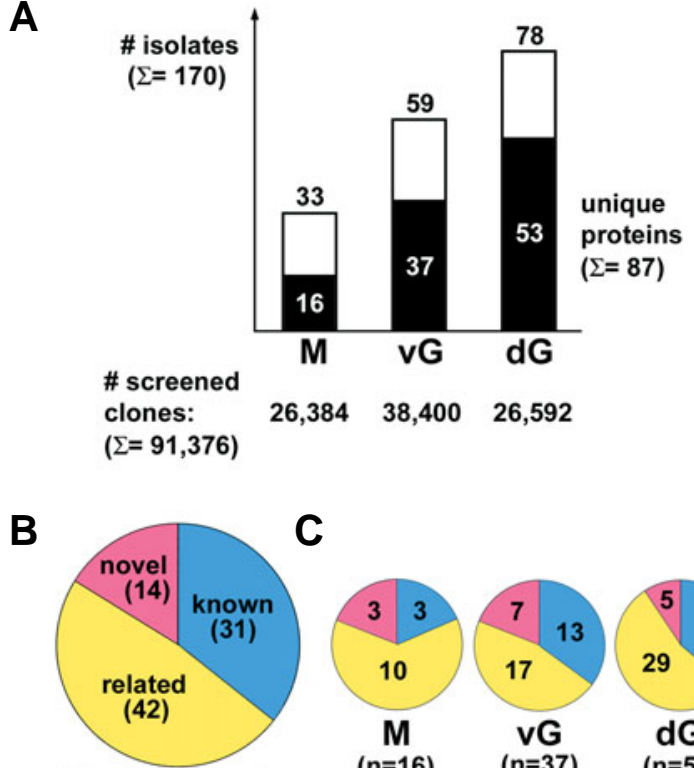

87 unique proteins

C

D
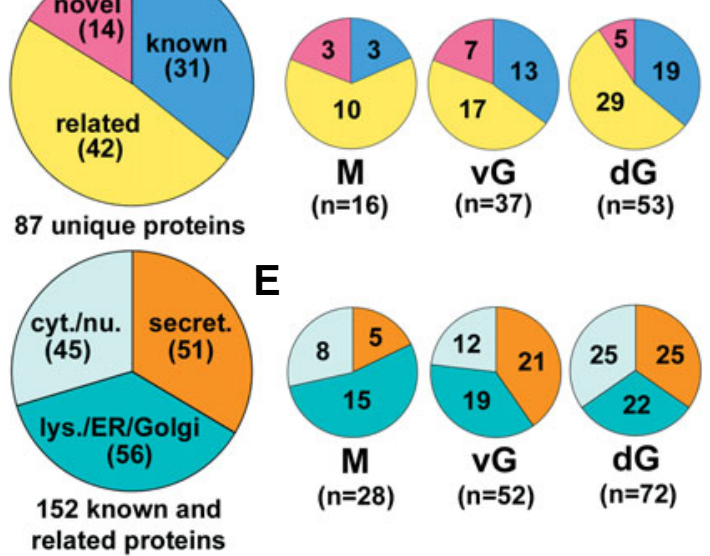

E

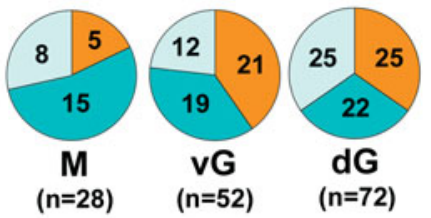


determine their identity. Since the three different cDNA libraries were almost equally represented among the total number of clones screened (with the exception of the ventralized gastrula library where clones were picked slightly above average), the overall yield of proteins showing reproducible bands and the proportion of unique sequences could be compared among the individual libraries. We retrieved 33 positive cDNA clones from the maternal library, 59 clones from the ventralized gastrula library and 78 clones from the dorsalized gastrula library. Within both gastrula stage libraries, two out of three isolated cDNAs on average were unique, while in the maternal library only every second sequence was unique. These observations indicated that screening of the gastrula libraries was more fruitful than of the maternally derived library.

We next determined the novelty of the proteins by comparing the sequences against public nucleotide and protein databases (Fig. 2B). Of the 87 unique sequences obtained, 31 clones (36\%)

TABLE 1

SUMMARY OF KNOWN XENOPUS GENES ISOLATED BY SECRETION CLONING

\begin{tabular}{|c|c|c|c|c|c|}
\hline Name & Family & Activity & $\begin{array}{l}\text { No. of } \\
\text { isolates }\end{array}$ & $\begin{array}{l}\text { Library } \\
\text { Acc. No. }\end{array}$ & GenBank \\
\hline \multicolumn{6}{|l|}{ Secreted } \\
\hline Noggin & & BMP inhibitor & 1 & vG & DN828606 \\
\hline Frzb-1 & sFRP & Wnt inhibitor & 3 & $v G, d G$ & DN828607 \\
\hline Sizzled & sFRP & Wnt/BMP inhibitor & 5 & $M, v G$ & DN828609 \\
\hline Cerberus & Cerberus & Nodal/BMP/Wnt inhibitor & 2 & $\mathrm{dG}$ & DN828648 \\
\hline DAN & Cerberus & BMP inhibitor & 1 & $d G$ & DN828649 \\
\hline Nodal related-3 & TGF $\beta$ superfamily & BMP/Activin inh.; FGFR act. & 4 & $d G$ & DN828650 \\
\hline Antivin/Lefty & TGF $\beta$ superfamily & Nodal/Activin inhibitor & 2 & $d G$ & DN828651 \\
\hline ADMP & TGF $\beta$ superfamily & Growth factor & 2 & $d G$ & DN828652 \\
\hline Glypican-4 & Heparan Sulphate Proteoglycan & Wnt/FGF co-receptor & 1 & $d G$ & DN828653 \\
\hline Lunatic Fringe & Glycosyltransferase & Notch modulator & 2 & vG & DN828610 \\
\hline Egg Envelope gp37/ZP1 & & & 1 & $v G$ & DN828611 \\
\hline Cortical Granule Lectin & Eglectin & & 1 & $v G$ & DN828612 \\
\hline Ferritin $\mathrm{H}$ & & & 1 & $d G$ & DN828654 \\
\hline \multicolumn{6}{|l|}{ Lysosomal/ER/Golgi } \\
\hline Cathepsin D & Asp protease & & 2 & $v G, d G$ & DN828613 \\
\hline TER-ATPase & AAA ATPase & Vesicle formation & 7 & $v G$ & DN828614 \\
\hline prenylated v-SNARE 1 & & Vesicle formation & 1 & $d G$ & DN828655 \\
\hline DG42 & Hyaluronan synthase & Glycosaminoglycan synthesis & 1 & $d G$ & DN828656 \\
\hline \multicolumn{6}{|l|}{ Cytoplasmic/Nuclear } \\
\hline 14-3-3 protein zeta & 14-3-3 protein & Cell cycle, signal transduction & 5 & $v G, d G$ & DN828657 \\
\hline 14-3-3 protein epsilon & 14-3-3 protein & Cell cycle, signal transduction & 1 & $d G$ & DN828658 \\
\hline 14-3-3 like protein & 14-3-3 protein & Cell cycle, signal transduction & 3 & $d G$ & DN828659 \\
\hline Strathmin & & Signal transduction & 1 & M & DN828586 \\
\hline Rho A & Small Rho-like GTPase & Cell adhesion, patterning & 1 & vG & DN828615 \\
\hline$\beta$-Actin & & Cytoskeleton & 1 & vG & DN828616 \\
\hline$\gamma$-Actin & & Cytoskeleton & 1 & M & DN828587 \\
\hline Ribonucleoprotein Alb & & RNA binding & 1 & $v G$ & DN828617 \\
\hline Poly(A) binding protein & & RNA binding & 1 & $d G$ & DN828660 \\
\hline Lactate Dehydrogenase B & Oxidoreductase & Glycolysis & 1 & $d G$ & DN828661 \\
\hline Aldolase C & Frc.-bisphosphate Aldolase & Glycolysis & 1 & $d G$ & DN828662 \\
\hline Glutamine Synthetase & & Amino acid biosynthesis & 1 & $d G$ & DN828663 \\
\hline RALDH2 & Oxidoreductase & Retinoic acid biosynthesis & 1 & $d G$ & DN828664 \\
\hline XDRP1 & & Cell cycle & 2 & $v G$ & DN828618 \\
\hline
\end{tabular}

M, maternal library (32-cell stage); vG, ventral gastrula stage library; dG, dorsal gastrula stage library. were already known Xenopus genes, 42 sequences (48\%) had a high degree of homology to previously characterized genes and 14 clones (16\%) were determined to be novel, i.e. showing little or no homology with sequences of known function. Within each library tested, the frequency of known proteins was lowest in the maternal library and significantly higher in the gastrula stage libraries (Fig. 2C). The percentage of novel proteins was similarly high in the maternal and ventralized gastrula library and relatively low in the dorsalized gastrula library. This result was not surprising, given that rather little attention has been given to Xenopus libraries at the cleavage stage, whereas due to the interest in the Spemann-Mangold organizer phenomenon, proteins present in the dorsal gastrula have been the target of numerous screens in the past.

A major criterion for the success of our screen was the amount of secreted proteins among the isolated clones. The predicted subcellular localization of proteins previously characterized in Xenopus or other vertebrates is shown in Figure 2D. Table 1 records the known Xenopus proteins isolated, Table 2 the clones related to proteins characterized in other organisms and Table 3 the novel proteins identified. Of 152 isolated known Xenopus or related sequences from other organisms, 51 clones (34\%) were reported as secreted proteins and 56 proteins $(37 \%)$ were normally localized in lysosomes, endoplasmic reticulum (ER) or the Golgi apparatus. Partial 5 ' sequences of these clones revealed that each of them contained a signal sequence characteristic of proteins destined for the secretory pathway. It is of interest to note that no plasma membrane-specific protein was isolated. The remaining 45 clones (30\%) were cytoplasmic or nuclear proteins and represented false positives, i.e. proteins not expected to be secreted. The high abundance of secreted proteins in our screen indicates that secretion cloning is an efficient method to enrich for extracellular proteins. We then compared the subcellular localization of previously characterized proteins for each library (Fig. $2 \mathrm{E})$. Notably, the percentage of secreted proteins was significantly lower in the maternal library than in the gastrula libraries. Concomitantly, the number of lysosomal, ER and Golgi proteins is relatively high in the library from 32-cell stage embryos. When all proteins are considered (including the novel ones with an authentic signal peptide), 
Fig. 3. xGra1 and $x G r a 2$ belong to the Granulin family of secreted growth factors. (A) Supernatant culture medium of human embryonic kidney (293T) cells transfected with cDNA encoding nonsecreted green fluorescent protein as control (GFP), Xenopus Granulin-1 (xGra1) or Xenopus Granulin-2 (xGra2). Cells were labeled with ${ }^{35}$ S-methionine and cysteine and their supernatants were analyzed by SDS-PAGE and autoradiography. Note that $X G r a 1$ is secreted as a $105 k D$ protein and $x G r a 2$ as an $82 k D$ protein. (B) Diagrams of $x G r a 1$ and $x G r a 2$. The signal peptide cleavage sites are indicated by triangles. The black boxes indicate conserved granulin repeats (Pfam accession number PF00396). The numbers and guidelines indicate repeats conserved in both proteins and are based on sequence similarities. Note that the granulin repeats 3,8 and 9 of $x$ Gra 1 are missing in $x G r a 2$. (C) Signature of the granulin repeat. Note the conserved spacing of four cysteine doublets flanked by two cysteine singletons on each side. (D) Sequence alignment of $x$ Gra1 and xGra2. $x$ Gra1 corresponds to the Granulin provisional protein sequence previously published for Xenopus laevis (GenBank accession number AAH48224) and xGra2 is novel (GenBank accession number DQ004683). Identical amino acid residues are shaded in black and similar or conserved residues in gray. Dots represent gaps introduced into the amino acid sequence in order to obtain optimal alignment. The signal peptide cleavage site as predicted by SignalP is indicated with an arrowhead. Black bars indicate the granulin repeats and the stars the conserved cysteine residues. The overall number of amino acids is indicated at the end of each sequence. (E-G) Expression of XGra2 analyzed by whole-mount in situ hybridization. (E) Four-cell stage embryo in animal view. Note the high level of maternal transcripts. (F) Embryo at late neurula stage in dorsal view showing spotted expression in the epidermis. (G) Early tail bud stage embryo in lateral view. Note expression in the pronephric glomus (gl).

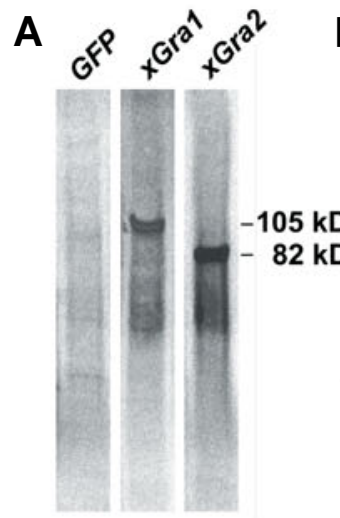

B

$5 \mathrm{kD}$

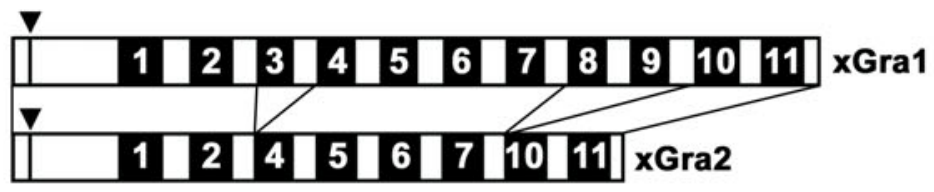

C
$\underline{\mathrm{C}} \mathrm{x}_{5-6} \underline{\mathrm{C}} \mathrm{x}_{5} \underline{\mathrm{CC}} \mathrm{x}_{8-9} \underline{\mathrm{CC}} \mathrm{x}_{6} \underline{\mathrm{CC}} \mathrm{x}_{5} \underline{\mathrm{CC}} \mathrm{x}_{5} \underline{\mathrm{C}} \mathrm{x}_{4-6} \underline{\mathrm{C}}$

D

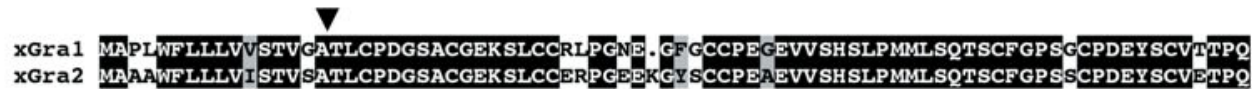
xGra1 GGSACCPMAOGRSCRDGHHCCSAGSYCSDDGHFCIPASNESAVI CPDGKSECPALTTCCLMSDMSSWGCCPMPQAVCCAD
xGra2 GGSACCPLTEGKSCQDGHHCCSSGSYCSDDGHYCIPASNQSAVVCPDCRSECPALTSCCLMSDMSSWGCCPMPEAVCCED

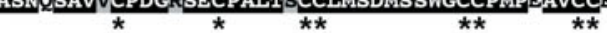

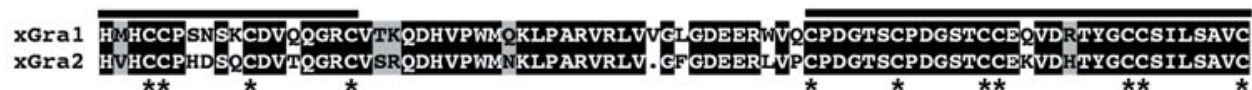
xGra 1 CSDHLHCCPAGTSCDLVHOKCVSSNGEGPLLLQMPAVR $Q$ ESANQVTLCDASTSCPDKNTCCRLLSGKFGCCPYDQAVCCED

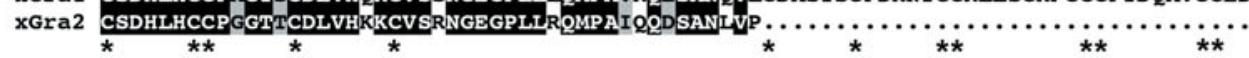
xGra1 QIHCCPNGFTCSDGSCVMAEHSI PWMKKTLAKGLTTTRVR CDETASCPEOETCCRLVSGKWGCCP IEKAVCCDDHLHCCP

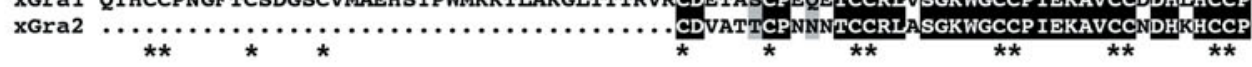
xGra 1 EGFTCTOGQCLAEEISIPWF SKTPALTHKARDV $Q$ CDDMYSCPDGQTCCRLASGDWGCCP IAKAVCCEDHEHCCPPGYTCS xGra2 EGYTCSIGKCSREEHSIPWLIKTPALTHKAGDVKCDDMYSCPDGQTCCILASGDWACCPIAQAVCCDDHEHCCPPGYTCS

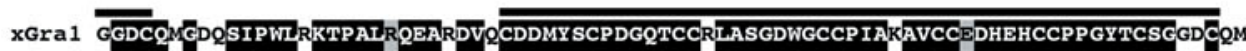
xGra2 EGDCQKGAISIPWISKTPALKQEAGDVKCDDMYSCPDGQTCCLLASGDWGCCPIAQAVCCDDHEHCCPPGYTCSGSOCMS

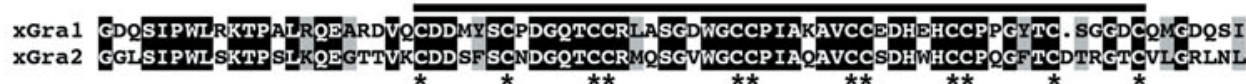
xGra1 PWIRKTPALRQEARDVQCDDMYSCPDGQTCCRLASGDWGCCPIAKAVCCEDHEHCCPPGYTCSGGDCQMGDQSIPWLRKT

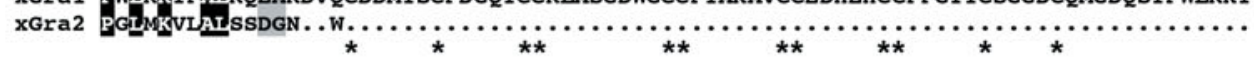
XGra1 PALRQEARDVQCDDMYSCPDGQTCCRLASGDWGCP IAKAVCCDDHEHCCPPGFTCSGAQCIGSGGGLSIPWFSRTPALR

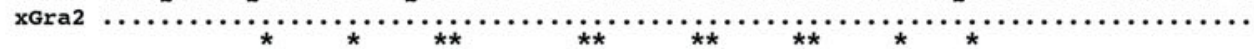

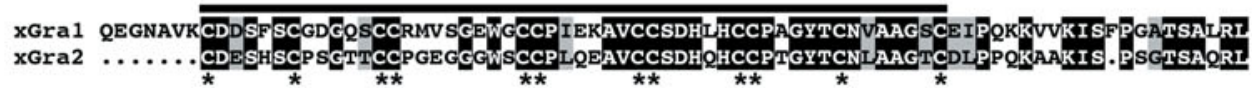
XGra1 NYVWCDAQTYCFDGQTCCRGRGGVWNCCIYTQGVCCPDMVHCCPYGYVCLAGGASCARSGMSRWDGKPSPPT 950

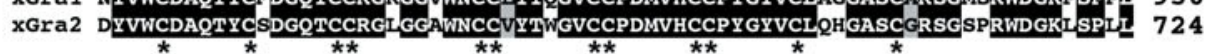
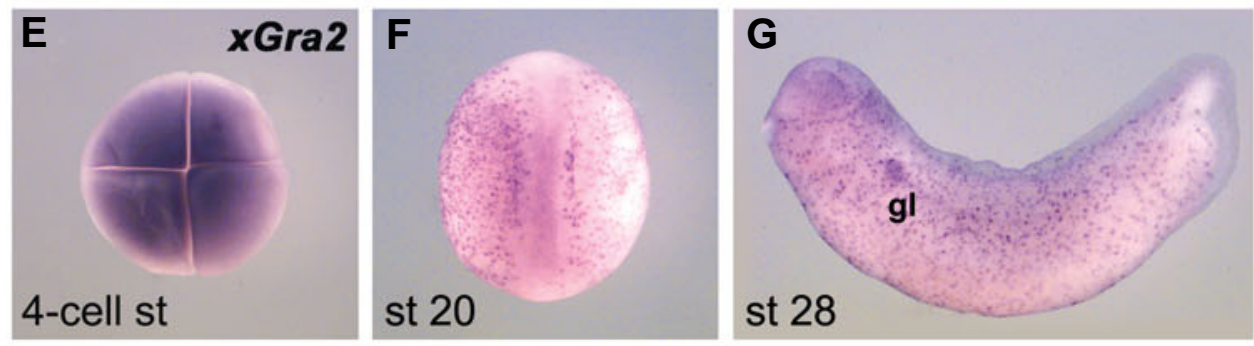
approximately 90 pools (each containing 16 cDNA clones) needed to be screened in order to retrieve one secreted protein. Chances of isolating a secreted protein were highest in the dorsalized gastrula library (one in 55 pools), half as big in the ventralized gastrula library (one in 96 pools) and more than three-fold lower (one in 183 pools) in the 32-cell stage library. These findings may reflect a lower need for extracellular communication at the cleavage stage compared with the intense crosstalk thought to take place between cells in the gastrulating embryo.

\section{Previously characterized Xenopus proteins}

\section{Known secreted proteins}

Interestingly, the majority of the known secreted proteins turned out to be soluble growth factor antagonists with important roles in development (Table 1). We identified Noggin, a protein that directly induces neural tissue and dorsalizes mesoderm by binding BMPs, preventing them from activating their receptors (Zimmermann et al., 1996). Frzb-1 and Sizzled are putative Wnt antagonists of the same family, that show homology to the extracellular domain of the Wnt receptor Frizzled (Leyns et al., 1997; Salic et al., 1997); subsequent studies suggested that Sizzled also acts by an unknown mechanism on the BMP pathway (Collavin and Kirschner, 2003). We identified the head inducer Cerberus that acts as a multivalent inhibitor of BMP, Wnt and Nodal signals (Piccolo et al., 1999). A Cerberus-related protein, called DAN, binds to BMP and restricts BMP signaling (Hsu et al., 1998). Three distinct members of the transforming growth factor$\beta$ (TGF $\beta$ ) superfamily were identified, two of which may act as antagonists. Xenopus Nodal-related-3 (Xnr3) lacks mesoderminducing activity, which is characteristic of other members of the Nodal family and directly induces neural tissue by inhibiting BMP signaling (Hansen et al., 1997); Xnr3 also regulates convergentextension movements through the FGF receptor (Yokota et al., 2003). Xenopus Antivin (Xatv, also called Lefty) suppresses mesoderm formation and specifies the left-right axis by antagonizing Nodal signaling (Cheng et al., 2000; Wessely et al., 2001). The Anti-Dorsalizing Morphogenetic Protein (ADMP) is a member of the BMP family, which likely acts as a positive signal through its BMP receptors and inhibits dorsal and anterior development (Moos et al., 1995; Dosch and Niehrs, 2000). The isolation of these proteins strongly supports the view that during early development, an important mechanism for regulating growth factor activity depends on the selective inactivation of signaling pathways by secreted antagonists that block specific ligand/receptor interactions.

We also identified Xenopus Glypican-4 (Xgly-4), which belongs to the family of heparan sulphate proteoglycans linked to the cell surface via a glycosylphosphatidylinositol (GPI) anchor; Xgly4 acts as a co-receptor for Wnt and FGF signals and in this way affects convergence-extension movements during gastrulation and dorsoventral patterning of the forebrain, respectively (Ohkawara et al., 2003; Galli et al., 2003). Lunatic Fringe (IFng) was isolated twice. It was originally described as a secreted protein that induces mesoderm formation in Xenopus embryos (Wu et al., 1996); recent studies have shown that IFng encodes a glycosyltransferase, which modulates Notch signaling (Moloney et al., 2000). Egg Envelope Glycoprotein gp37 constitutes a major component of the egg envelope, an extracellular matrix that surrounds growing oocytes, ovulated eggs and early embryos and is related to the mammalian zona pellucida component ZP1 (Kubo et al., 2000). Cortical Granule Lectin is a calcium-dependent, galactosyl-specific member of the new eglectin family that prevents polyspermy by forming the fertilization layer of the egg envelope (Chang et al., 2004). Finally, heavy-chain Ferritin (Ferritin $\mathrm{H}$ ) was found; although Ferritin $\mathrm{H}$ is primarily a cytosolic protein involved in iron storage, extracellular Ferritin $\mathrm{H}$ has been found in blood and other body fluids (Ghosh et al., 2004). The isolation of these known bona fide secreted proteins, many of them encoding important signaling factors, is a good indication for the success of the screen. All clones are full-length and can be expressed as transfected DNA, synthetic mRNA or used as in situ hybridization probes. They constitute a valuable resource for Xenopus researchers.

\section{Known lysosomal/ER/Golgi proteins}

In addition, we isolated proteins known to be localized in lysosomes or other compartments of the secretory pathway such as ER or Golgi apparatus. Cathepsin D is an aspartate protease usually restricted to lysosomes (Katz and Taichman, 1999). Seven isolates encoded the transitional endoplasmic reticulum ATPase (TER ATPase), a member of the AAA (ATPases associated with a variety of cellular activities) protein family that contributes to membrane fusion and vesicle formation (Peters et al., 1990). The prenylated vesicle-associated SNARE (v-SNARE) is localized to the ER-Golgi network and plays a role in membrane formation (Park et al., 1998). Xenopus DG42 is a ventrally expressed hyaluronan synthetase involved in the synthesis of glycosaminoglycans, which provide a hydrophilic medium in the extracellular space (Rosa et al., 1988; Wessely et al., 2004).

\section{Cytoplasmic and nuclear proteins}

In our secretion screen, we also isolated proteins that are normally localized in the cytoplasm or in the nucleus. They usually appeared as weak but distinct bands in the supernatant of transfected and radioactively labeled cells. Cytoplasmic and nuclear proteins may have artificially entered the secretory pathway and in this or by alternative pathways exited the cells, or they may have been released by dying cells. In a few cases, secretion of these proteins has been reported before, such as for members of the 14-3-3 protein family, which normally act as cytoplasmic chaperones for a variety of signaling proteins. We isolated five clones of 14-3-3 protein zeta, a single clone of 14-3-3 protein epsilon and three clones of 14-3-3-like protein in the supernatant of transfected human embryonic kidney 293T cells. 14-3-3 proteins have previously been identified in the medium of cultured keratinocytes (Katz and Taichman, 1999) and in the secretions of parasitic flatworms (Siles-Lucas et al., 2000), suggesting that these proteins may get secreted in vitro and in vivo.

\section{Sequences homologous to proteins characterized in other species}

\section{Related secreted proteins}

We have previously presented the gene expression and functional studies on two new members of the secreted Frizzledrelated protein (sFRP) family in Xenopus, sFRP-2 and Crescent, which add to the growing list of putative growth factor antagonists 
TABLE 2

XENOPUS SEQUENCES RELATED TO GENES PREVIOUSLY IDENTIFIED IN OTHER VERTEBRATES

\begin{tabular}{|c|c|c|c|c|c|c|}
\hline Name & Family & Activity & $\begin{array}{c}\text { No. of } \\
\text { isolates }\end{array}$ & Library & Species & $\begin{array}{l}\text { GenBank } \\
\text { Acc. No. }\end{array}$ \\
\hline \multicolumn{7}{|l|}{ Secreted } \\
\hline sFRP-2 & sFRP & Wnt inhibitor & 3 & $v G, d G$ & X. laevis & AF255339 \\
\hline Crescent & sFRP & Wnt inhibitor & 1 & $v G$ & X. laevis & AF255340 \\
\hline IGFBP-5 & IGF binding protein & IGF modulator & 1 & $d G$ & X. laevis & AY052629 \\
\hline HtrA1 & HtrA, Serine protease & BMP/TGF $\beta$ inhibitor & 2 & vG & Mouse & DN828588 \\
\hline Proteinase inhibitor Nexin-1 & Ser protease inh. (Serpin) & & 5 & $v G, d G$ & Rat & DN828589 \\
\hline Nucleobindin & EF-hand Ca2+-bindg. prot. & & 3 & $M, v G, d G$ & Rat & DN828619 \\
\hline Cyclophilin B & Peptidyl-prolyl isomerase & & 2 & $d G$ & Human & DN828620 \\
\hline Autotaxin & Exo-Phosphodiesterase & & 1 & $d G$ & Human & DN828621 \\
\hline TCTP & Small chaperon & & 5 & $M, d G$ & Human & DN828622 \\
\hline TRAP-5b & Acid phosphatase & & 2 & $d G$ & Human & DN828623 \\
\hline \multicolumn{7}{|l|}{ Lsyosomal/ER/Golgi } \\
\hline Cathepsin B & Cys protease, papain & Protein metabolism & 7 & $v G, d G$ & Mouse & DN828590 \\
\hline Cathepsin L & Cys protease, papain & Protein metabolism & 19 & $\mathrm{M}, \mathrm{vG}, \mathrm{dG}$ & Fish & DN828624 \\
\hline Prosaposin & & Lipid met.; neurotroph. fact. & 3 & $v G, d G$ & Chick & DN828591 \\
\hline$\alpha$-Mannosidase & Glycosylhydrolase & Carbohydrate metabolism & 1 & $v G$ & Human & DN828592 \\
\hline$\beta$-Hexosaminidase $B$ & Glycosidase & Carbohydrate metabolism & 1 & M & Mouse & DN828578 \\
\hline CHMP-1 & & Vesicle trafficking & 1 & vG & Human & DN828593 \\
\hline Rab GDP dissociation inhibitor & GTPase activating protein & Vesicle trafficking & 1 & $d G$ & Chick & DN828625 \\
\hline Retinol Dehydrogenase-10 & Epimerase & Retinoic acid biosynthesis & 1 & $d G$ & Mouse & DN828626 \\
\hline Transaldolase & & Carb. met., pentose pathway & 2 & $M, v G$ & Human & DN828594 \\
\hline Ribulose-5-P-3-epimerase & Epimerase & Carb. met., pentose pathway & 1 & $d G$ & Human & DN828627 \\
\hline EDJ & HSP40, DnaJ & Chaperone & 1 & $d G$ & Mouse & DN828628 \\
\hline 47kD Heatshock Protein & Serpin & Chaperone & 1 & $d G$ & Mouse & DN828629 \\
\hline Torsin B & AAA ATPase & Chaperone & 2 & vG & Human & DN828595 \\
\hline Protein Disulphide Isomerase & Oxidoreductase & Chaperone & 1 & $d G$ & Human & DN828630 \\
\hline ER KDEL Receptor & & Protein sorting & 1 & $d G$ & Human & DN828631 \\
\hline ERGIC-53 & Legume-like Lectin & Glycoprotein transport & 1 & M & Rat & DN828579 \\
\hline VIP36 & Legume-like Lectin & Glycoprotein transport & 1 & $d G$ & Mouse & DN828632 \\
\hline \multicolumn{7}{|l|}{ Cytoplasmic/Nuclear } \\
\hline 14-3-3 Protein theta & 14-3-3 Protein & Cell cycle, signal transduction & 1 & $d G$ & Mouse & DN828633 \\
\hline Tropomyosin & & Cytoskeleton & 1 & $v G$ & Rat & DN828596 \\
\hline Protein Phosphatase $\mathrm{X}$ & Ser/Thr Prot. Phosphatase & Microtubule nucleation & 1 & $v G$ & Rabbit & DN828597 \\
\hline Phosphoglycerate Mutase & Mutase & Glycolysis & 4 & $M, d G$ & Rat & DN828580 \\
\hline Pyruvate Kinase & Phosphotransferase & Glycolysis & 3 & $d G$ & Chick & DN828634 \\
\hline Fructose-1,6-bisphosphatase & Hydrolase & Gluconeogenesis & 1 & $d G$ & Human & DN828635 \\
\hline Malate Dehydrogenase & Dehydrogenase & Tricarboxylic acid cycle & 1 & $d G$ & Cat & DN828636 \\
\hline Serine Hydroxymethyltransferase & Methyltransferase & Amino acid metabolism & 2 & $M, d G$ & Sheep & DN828637 \\
\hline Guanidinoacetate Methyltransferase & Methyltransferase & Creatine biosynthesis & 1 & $d G$ & Rat & DN828638 \\
\hline Uroporphrinogen Decarboxylase & Decraboxylase & Heme biosynthesis & 1 & $d G$ & Fish & DN828639 \\
\hline Adenylosuccinate Lyase & Lyase & Purine biosynthesis & 4 & $\mathrm{M}, \mathrm{vG}, \mathrm{dG}$ & Chick & DN828598 \\
\hline Aldehyde Reductase-1 & Aldo/Keto Reductase & & 1 & $v G$ & Rat & DN828599 \\
\hline Prolidase & Peptidase & & 1 & $d G$ & Mouse & DN828640 \\
\hline SMARC & SWI/SNF & Chromatin remodeling & 1 & vG & Human & DN828600 \\
\hline Heat shock factor binding protein-1 & & Transcription factor & 1 & M & Human & DN828581 \\
\hline
\end{tabular}

For abbreviations, see Table 1.

secreted by the Spemann-Mangold organizer (Pera and De Robertis, 2000). Furthermore, we obtained the Xenopus homolog of IGF binding protein-5 (IGFBP5) that promotes head development by stimulating IGF signaling (Pera et al., 2001). We now present a novel Xenopus homolog of HtrA1 (Table 2), which encodes a secreted serine protease with an IGF-binding motif (Clausen et al., 2002). In addition, we isolated Xenopus Protease Nexin-1 (PN-1), a secreted serine protease inhibitor of the serpin superfamily (Küry et al., 1997). We also isolated a new Xenopus homolog of Nucleobindin, a signal peptide containing EF-hand 
A

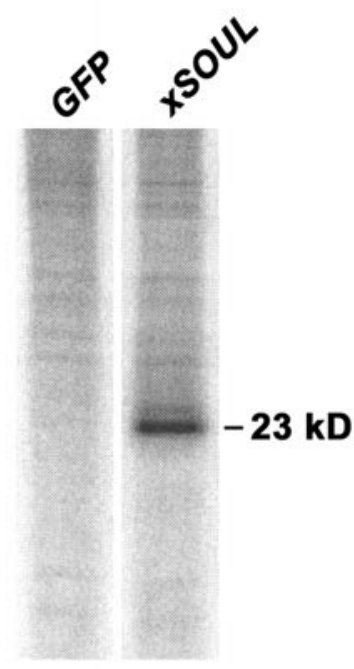

B

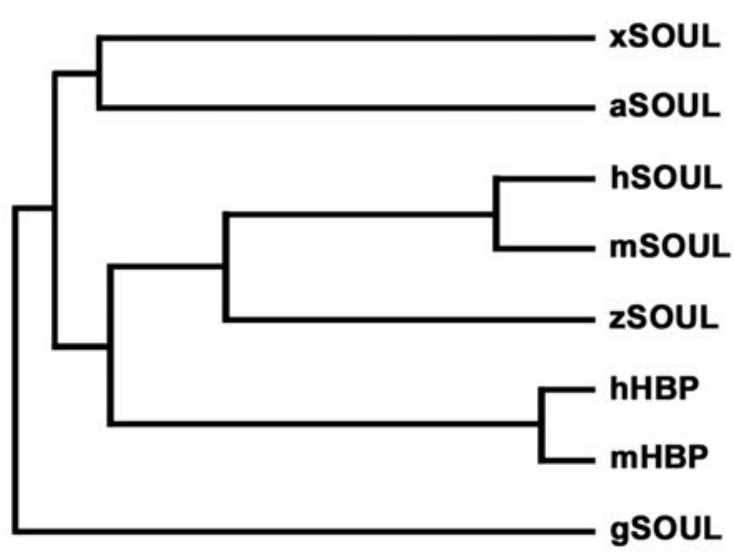

C

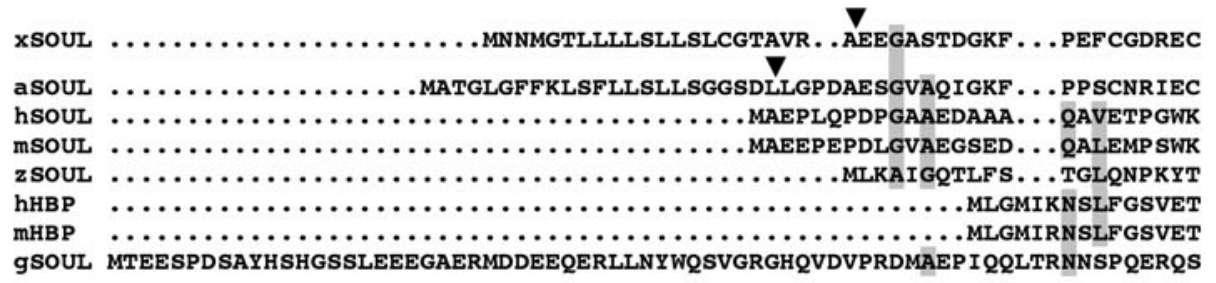

xSOUL PKFHLVQQYD......SFELRAYEGTOWVTTE. LDDGFLGFMVTSFRRLFNYISGKNSOGIKIEMTVPVT a SOUL PSYELVHSGN $\ldots \ldots$ GYEIRRYNNTVWVSTEPIPDI SLVDATRTAFFOLFAY I OGKNEYHQKIEMTAPVI
hSOUL APEDAGPQPG...... SYEIRHYGPAKWVSTS. VESMDWDSAIOTGFTKLNSY IOGKNEKEMKIKMTAPVT

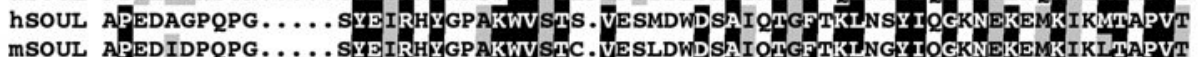
z SOUL AQESKGDD........ YEVRTYQATNWVSTV. VTGMEQDQAMSTGGRRLFKYIOGSNEKKSKVEMTTPVS hHBP WPWQVLSKGDK. EEVAYEERACEGGKFTVE.VTDKPVDEALREAMPKVAKYAGGTNDKGIGMGMTVPIS MHBP WPWQVLSTGGK. EDVSYEERACEGGKFATVE. VTDKPVDEALREAMPKIMKYVGGTNDKGVGMGMTVPVS
gSOUL IPFTLIQRKEKLGDLIYEKRQYGKAKWACIK. MKEKQYESICLGFMKLMRYICEQNSSGLYLIIIPIV

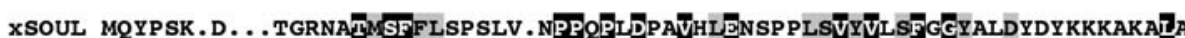
asOUL SQVSPS. DGPFCESSFTVSFYVPKKNQ. PDPAPSEN. LHI IKWN SRYVAVROF SGFVSDDSI GEQAAALD hSOUL SYVEPG. SGPFSESTITISIY IP SEQQFDPPRPLESDVFIEDRAEMTVFVRSFDGF SSAQKNQEQLLTLA mSOUL SYVEPG. SSPF SESTITI SLY IP SEQ QPDPPRPSESDVF IEDRAEMTVFVRSFDGF SSGQKNQEQLLTLA z SOUL CLIDPG. AGPACESTFTVSFY Y EEEHQADPPKPTDPDVFIESRKELTAFVRTFGGFANSESCCEEILKLI hHBP FAVFPNEDGS.LQKKLKVWFRIPNQF OSDPPAPSDKSVKIEEREGITVY SMQF GGYAKEADYVAQATRLR MHBP FAVFPNEDGS.LQKKLKVWFRIPNQF OGSPPAP SDESVKIEEREGITVYSTOFGGYAKEADYVAHATOLR gSOUL TIVHTNESOSEMRQAVTVAYY YPEVLQDQPPHPFDSDIIIEEWPSTIVYSRSFRGITNEDSIMRE INLLA

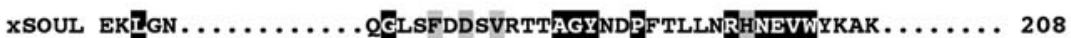
asOUL SSLKGTAWANAIAKSKEDGGVGSDSAYTVAQYNSPFEF SGRVNEIWLPFELDV $\ldots \ldots 232$ hSOUL SILRE........... DGKVFDEKVYYTAGYNSPVKLLNRNNEVWLIOKNEPTKENE 205 MSOUL NILRE $\ldots \ldots \ldots \ldots$ EGKVFNEKVFYTAGY SSPFQLLDRNNEVWLIQKNEPSVENK 205 zSOUL ESLKR.......... DGMKFKEAPYYRAGYDSPFKLTGRRNEVWLIKDEE ..... 190 hHBP AALEG........... PATYRGDIYFCTGYDPPMKPYGRRNEIWLLKT . . . 189 MHBP TTLEGT. . . . . . . . PATYQGDVYYCAGYDPPMKPYGRRNEVWLVKA. . . . . . 190 gSOUL EILES.......... PELCLQDTFI IAGYTNPAAA. NRHNEIWFLQRP..... 246
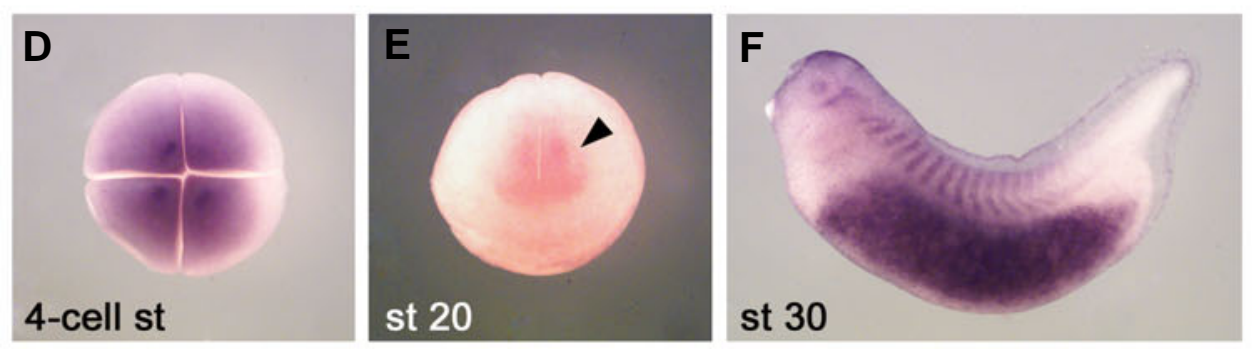

calcium-binding protein, which is known to be secreted, since the protein has been found in the bone extracellular matrix, blood serum and the supernatant of cultured cells (Lavoie et al., 2002). Another extracellular protein found in our screen was Xenopus Cyclophilin B; cyclophilins were initially identified as binding proteins for the immunosuppressive drug cyclosporin $A$ and possess peptidyl-prolyl isomerase activity thought to participate in protein folding and leukocyte chemotaxis (Bukrinsky, 2002). We found a novel Xenopus protein related to Autotaxin, also termed tumor cell motilitystimulating protein; this glycoprotein is synthesized as a transmembrane protein, but upon cleavage is released as a soluble phosphodiesterase to activate cellular motility (Murata et al., 1994). Another clone encoded the Xenopus homolog of the translationally controlled tumor protein (TCTP); this molecule is highly conserved in eukaryotes, shares similarity with small chaperones and functions in cell cycle progression, malignant transformation and protection against apopto-

Fig. 4. xSOUL is a novel secreted protein of the SOUL/Heme-binding protein family. (A) Culture medium of 293T cells transfected with green fluorescent protein CDNA as control ( GFP) or Xenopus SOUL cDNA (xSOUL). xSOUL is secreted as a $23 \mathrm{kD}$ protein. (B) Evolutionary relationship of XSOUL and other members of the SOUL/heme binding protein (HBP) family. Proteins with the greatest sequence similarity cluster together and branch lengths are proportional to distance (TreeTop-Phylogenetic Tree Prediction; http://www.genebee.msu.su/services/phtree_reduced.html). Only the mature proteins have been considered. Note thatXSOUL is most closely related to a derived family member in the plant Arabidopsis thaliana (aSOUL). The listed proteins have the following GenBank accession numbers: xSOUL (GenBank accession number DQ004682); aSOUL (NM101570); human SOUL (AF117616); mouse SOUL (AF117614); zebrafish SOUL (BC045936); human HBP (AF117615); mouse HBP (AF117613); chick SOUL (AF117612). (C) Comparison of xSOUL with other SOUL/HBP sequences. Note that only XSOUL and aSOUL have cleavable signal peptides (triangle). The putative hemebinding region as reported by Zylka and Reppert (1999) is overlined. (D) Four-cell stage embryo in animal view showing maternal expression of xSOUL. (E) Anterior view of advanced neurula. Note weak expression in the anterior brain (arrowhead). (F) Tailbud stage embryo with distinct expression in the forebrain, lens, somites and gut. 
sis. TCTP also displays extracellular cytokine-like activities and induces the production of histamine and interleukins (Bommer and Thiele, 2004). A Xenopus homolog of the tartrate-resistant acid phosphatase (TRAP) has been isolated; in mammals, TRAP is secreted from osteoclasts into the circulation (Alatalo et al., 2000).

\section{Clones related to lysosomal/ER/Golgi proteins}

A large proportion of the Xenopus clones that exhibit homology to non-secreted proteins of the secretory pathway encoded cysteine proteases of the Cathepsin family. We isolated seven clones of a protein most similar to Cathepsin B and even nineteen isolates of a protein related to Cathepsin L. Secretion of lysosomal enzymes in tissue culture has been known for a long time (Hasilik, 1992) and members of the Cathepsin family have previously been reported to be secreted by epidermal keratinocytes in culture (Katz and Taichman, 1999). Three other isolates were related to Prosaposin, the precursor of the lysosomal Saposin proteins, which are essential for hydrolysis of glycosphingolipids; Prosaposin has also been suggested as a neurotrophic factor in the brain (O'Brien et al., 1994). We identified two new Xenopus homologs of lysosomal glycosidases ( $\alpha$-Mannosidase and $\beta$-Hexosaminidase $B$ ). $\alpha$-Mannosidase is required for degradation of asparagine-linked carbohydrates of glycoproteins and its deficiency in human and other mammals results in the lysosomal storage disorder $\alpha$-mannosidosis (Sun and Wolfe, 2001). Lysosomal $\beta$ Hexosaminidases are indispensable for degradation of gangliosides (an essential class of outer-layer membrane lipids) and mutations in the human $\beta$-Hexosaminidase $B$ subunit cause the lysosomal storage disorder Sandhoff disease (Maier et al., 2003). The isolation of both enzymes in our secretion screen is not surprising, given that secretion of $\alpha$-Mannosidase has been reported from cultured cells (Sun and Wolfe, 2001) and $\beta$-Hexosaminidase $B$ has been found in human serum (Isaksson and Hultberg, 1995).
We isolated the Xenopus homolog of CHMP1 (charged multivesicular body protein-1) that localizes to the endosome and plays a role in vesicle trafficking (Howard et al., 2001). The RabGDP-dissociation inhibitor (RabGDI) modulates membrane association of various Rab GTPases, which are key regulators of vesicular protein transport (Bartz etal., 2003). We also cloned the Xenopus homolog of Retinol Dehydrogenase-10 (RDH10), which is abundant in microsomes and involved in the synthesis of retinoic acid (Wu etal., 2002). We detected two components of the pentose phosphate pathway in Xenopus (Transaldolase, Ribulose-5-phosphate-3-epimerase). Although enzymes of this pathway are cytoplasmic, they have also been localized to the ER of mammals (Bublitz and Steavenseon, 1988). Four Xenopus proteins isolated were related to the molecular chaperones EDJ, HSP47, Torsin A and Protein Disulphide Isomerase that are normally found in the lumen of the ER. EDJ (for ER-associated DNAJ) is a heat shock protein of the HSP40 family involved in protein synthesis, folding and secretion (Yu et al., 2000). The 47kD heat shock protein (HSP47) is a chaperone derived from the serpin family and important for the processing and/or secretion of procollagen (Dafforn et al., 2001). Torsin B is a member of the AAA ATPase family expressed in the ER and is involved in protein transport and degradation; mutations in human Torsin B may lead to early-onset distonia and torticallis, a neurological disorder characterized by abnormal movements (McNaught et al., 2004). The Protein Disulphide Isomerase isolated belongs to the family of oxidoreductases and catalyzes the formation, isomerization and reduction of disulphide bonds (Jessop et al., 2004). In addition, we found the Xenopus homolog of the mammalian KDEL endoplasmic reticulum retention receptor that retains soluble ER chaperones with the carboxyterminal Lys-Asp-Glu-Leu (KDEL) sequence in the ER by retrieving them from later stages in the secretory pathway (Yamamoto et al., 2003). We also isolated two Xenopus homologs of the Lectin family (ERGIC-53, VIP36). Lectins are non-enzymatic carbohydrate-binding proteins with a

TABLE 3

NOVEL SEQUENCES OBTAINED THROUGH SECRETION CLONING

\begin{tabular}{|c|c|c|c|c|c|c|c|c|}
\hline Name & Family & Putative activity & $\begin{array}{c}\text { No. of } \\
\text { isolates }\end{array}$ & Library & Best hit & Species & $\begin{array}{l}\text { GenBank } \\
\text { Acc. No. }\end{array}$ & References \\
\hline \multicolumn{9}{|l|}{ Secreted } \\
\hline Isthmin & Thrombospondin-rel. & & 1 & $d G$ & Isthmin & $X$. laevis & AV091635 & Pera et al., 2002 \\
\hline Darmin & Glu-Carboxypeptidase & Zn-Metalloprotease & 1 & $v G$ & Glu carboxypeptidase Darmin & $X$. laevis & AY166869 & Pera et al., 2003 \\
\hline Darmin-r & Glu-Carboxypeptidase & Zn-Metalloprotease & 1 & M & EST Darmin-related & X. laevis & BU993920 & Pera et al., 2003 \\
\hline Granulin-1 & Granulin/Epithelin & Growth Factor & 1 & $v G$ & Granulin & X. laevis & DN828601 & this paper \\
\hline Granulin-2 & Granulin/Epithelin & Growth Factor & 1 & $v G$ & Hyp. prot. LOC443608 & X. laevis & DQ004683 & this paper \\
\hline SOUL & & & 5 & $\mathrm{M}, \mathrm{dG}$ & TEgg032m12 & X. tropicalis & DQ004682 & this paper \\
\hline Xystatin & Cystatin family & Cys protease inhibitor & 1 & $v G$ & Egg-white cystatin & Quail & DQ004681 & this paper \\
\hline Trinein & Kunitz/Serpin & Ser protease inhibitor & 1 & $d G$ & Clone S10-40-F7 mRNA & X. laevis & DN828641 & this paper \\
\hline ARMET & & & 1 & $\mathrm{dG}$ & ARMET protein & $X$. laevis & DN828642 & this paper \\
\hline LAMA-like & Laminin A-rel. & & 1 & M & Hyp. prot. LOC196463 & Human & DN828582 & this paper \\
\hline \multicolumn{9}{|c|}{ Non-secreted } \\
\hline LZ1601/10 & & & 1 & $v G$ & Hyp. Prot. MGC78953 & $X$. laevis & DN828602 & this paper \\
\hline LZ1665/1 & & & 1 & $v G$ & TEgg024e02 & X. tropicalis & DN828603 & this paper \\
\hline LZ2383/11 & & & 1 & $v G$ & Hyp. Prot. MGC84563 & $X$. laevis & DN828604 & this paper \\
\hline OW500/12 & & & 1 & $d G$ & Hyp. Prot. MGC80796 & $X$. laevis & DN828643 & this paper \\
\hline
\end{tabular}


role in quality control and protein traffic along the secretory pathway (Hauri et al., 2000). ER-Golgi intermediate compartment (ERGIC)-53 is a mannose-binding type 1 transmembrane protein that operates as a cargo receptor in the transport of glycoproteins from the ER to the Golgi. The related vesicular integral membrane protein (VIP36) may operate in quality control of glycosylation in the Golgi apparatus. Thus our screen identified many components of the secretory pathway in Xenopus, several of which regulate the processing, secretion and intracellular transport of proteins.

\section{Novel secreted proteins}

Our screen identified ten unique cDNA sequences encoding novel secreted proteins (Table 3 ). Some of these proteins may have already been deposited as Xenopus sequences in public
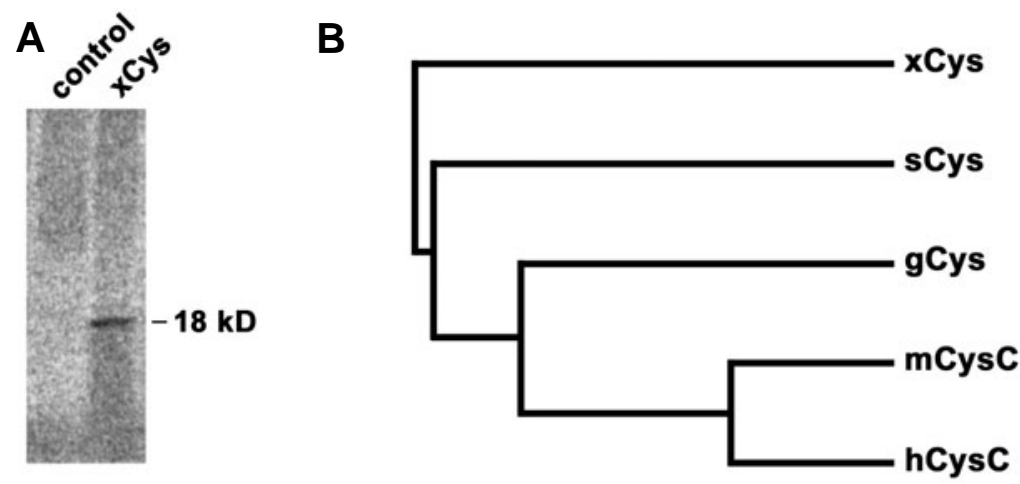

\section{C}

xCys ... MDAAVVFVVLVVAAGASA ....... SRGGMLIGGQYPASEHEQGVQ gCYS MAGARGCVVLLAAALMLVGAVLG ..... SEDRSRLLGAPVPVDENDEGLQ mCYSC MASPLRSLLFLLAVLAVAWA ........ ATPKQGPRMLGAPEEADANEEGVR hCYSC MAGPLRAPLLLLAILAVALAVSPAAG SSPGKPPRLVGGPMDASVEEEGVR sCYs ...MIMEWKIVVPLLAVAFTVANA ........ GLVGGPMDAMMNDQGTR
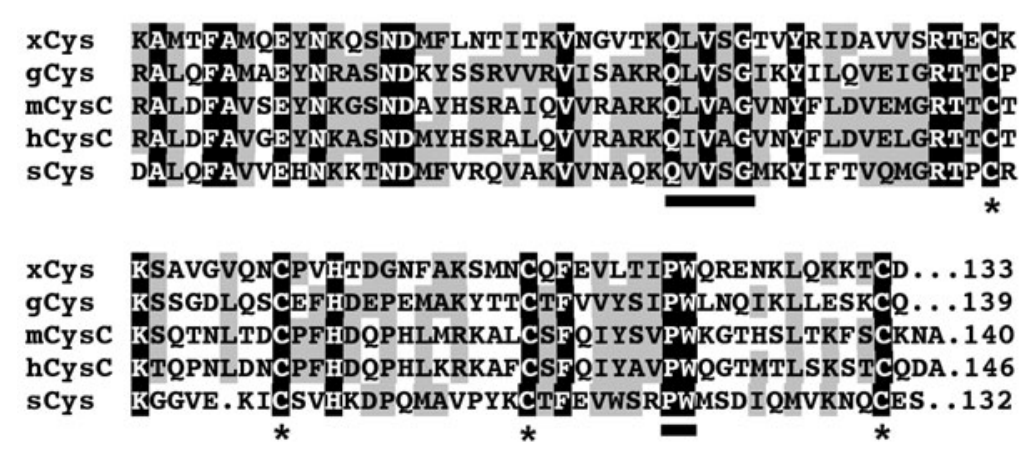

Fig. 5. Xystatin is a novel secreted cysteine proteinase inhibitor. (A) Supernatant of 293T cells non-transfected (control) or transfected with Xenopus Cystatin cDNA (xCys). Note that $x$ Cys is secreted as an $18 \mathrm{kD}$ a protein. (B) Phylogenetic tree indicating the relationship of $x C y s$ with other members of the cystatin superfamily. Only the mature proteins lacking the signal peptide have been aligned. GenBank accession numbers are as follows: Xystatin (D0004681); salmon Cystatin (D86628); chick Cystatin (JO5077); murine Cystatin-C (NM009976); human Cystatin-C (BC013083). (C) Sequence alignment of Xcys and related members of the cystatin superfamily. Four conserved cysteine residues known to form two disulphide bonds are labeled with stars. The conserved active site sequence $Q \times V \times G$ and pro-trp (PW) sequences are underlined (Brown and Dziegielewska, 1997). databases, or they may have homolgy to known sequences in ther organisms. Nevertheless, we regard them as novel in the the criteria for classifying a novel protein as secreted. of secreted protein in the supernatant of transfected previously presented three novel proteins isolated by secretion oning. Isthmin is a novel secreted protein with a thrombospondin

(Drm-r) are both Glutamate Carboxypeptidases; while rm contains a predicted signal peptide and is heavily released fected cells, Drm-r lacks an apparent signal peptide and is only poorly secreted (Pera et al., 2003). Trinein encodes a serine protease inhibitor of the Kunitz-type (O.W., José Garcia-Abreu, E.M.P and E.M.D.R., manuscript in preparation).

Xenopus ARMET-like exhibits similarity to ARMET (arginine-rich, mutated in early stage tumors), a protein susceptible to mutations in various human cancers (Shridhar et al., 1997). ARMET is highly conserved and homologs in mouse (GenBank accession number NP083379), Drosophila (GenBank accession number AAD32615) and C. elegans (GenBank accession number NP500273) have cleavable signal peptides and are predicted to be extracellular (PSORT II). We detected Xenopus ARMET-like as a strongly secreted protein of $20 \mathrm{kD}$ in the supernatant of cultured cells (data not shown), which matches the predicted molecular weight of $C$. elegans ARMET-like protein $(19 \mathrm{kD})$. The normal function of ARMET is unknown. An additional novel protein shows similarity to the secreted C. elegans Laminin A precursor (Evalue 2e-30; GenBank accession number NP499668) and Drosophila LAMA (lamina ancestor; E-value 3e18; GenBank accession number AAB49926; Perez and Steller, 1996) and is consequently referred to as LAMA-like. We detected LAMA-like as a $70 \mathrm{kD}$ protein in the supernatant of cultured cells (data not shown), which matches the predicted molecular weights of $C$. elegans Laminin A precursor (65.4 kD) and Drosophila LAMA (69 kD, Perez and Steller, 1996).

\section{Two novel growth factors of the Granulin family in Xenopus}

We found two putative growth factors of the granulin or epithelin family, termed Xenopus Granulin (xGra)1 and xGra-2 (Fig. 3). Granulins are candidate growth factors discovered in human leukocytes. They exhibit both proliferative and antiproliferative effects on epithelial cell lines. Members of this family share structural similarity with epidermal growth factor (EGF) and TGF $\alpha$. Both Granulin and EGF are cysteine-rich peptides of approximately $6 \mathrm{kD}$. Although dissimilar in their amino acid sequence, they show a common tertiary structure. The precursors of mammalian granulins and EGF are both organized as tandem 
repeats of conserved cysteine modules. The $6 \mathrm{kD}$ peptide forms, the intact precursor and the related TGF $\alpha$ protein regulate cell growth (Bhandari et al., 1992; Bateman and Bennett, 1998).

xGra1 and xGra2 were strongly secreted as intact precursors by transfected 293T cells, with xGra1 exhibiting a molecular weight of $105 \mathrm{kD}$ and $x \mathrm{Gra} 2$ of $82 \mathrm{kD}$ (Fig. 3A). x Gra1 is identical to a cDNA sequence, which has been previously deposited in the NCBI database (GenBank accession number BC048224) and encodes a protein of 950 amino acids with eleven copies of the granulin domain (Fig. 3B, upper panel). The novel $x$ Gra2 sequence yields a smaller protein (724 amino acids) with only eight granulin repeats (Fig. 3B, lower panel). The granulin domains of $x$ Gra1 and $x$ Gra2 show the characteristic spacing of 12 cysteines with four cysteine doublets flanked by two singletons, as indicated in Fig. 3C. The alignment of the two proteins reveals a conserved signal peptide cleavage site (between positions 16 and 17) and an overall amino acid identity of $76 \%$ (Fig. 3D). Closer examination of the amino acid sequences indicates that among the 11 granulin repeats present in $\times G r a 1$, the granulin repeats 3,8 and 9 are missing in $x$ Gra2 (Figs. 3 $B, D)$.

We analyzed the expression of the novel $x$ Gra2 gene during early Xeno-
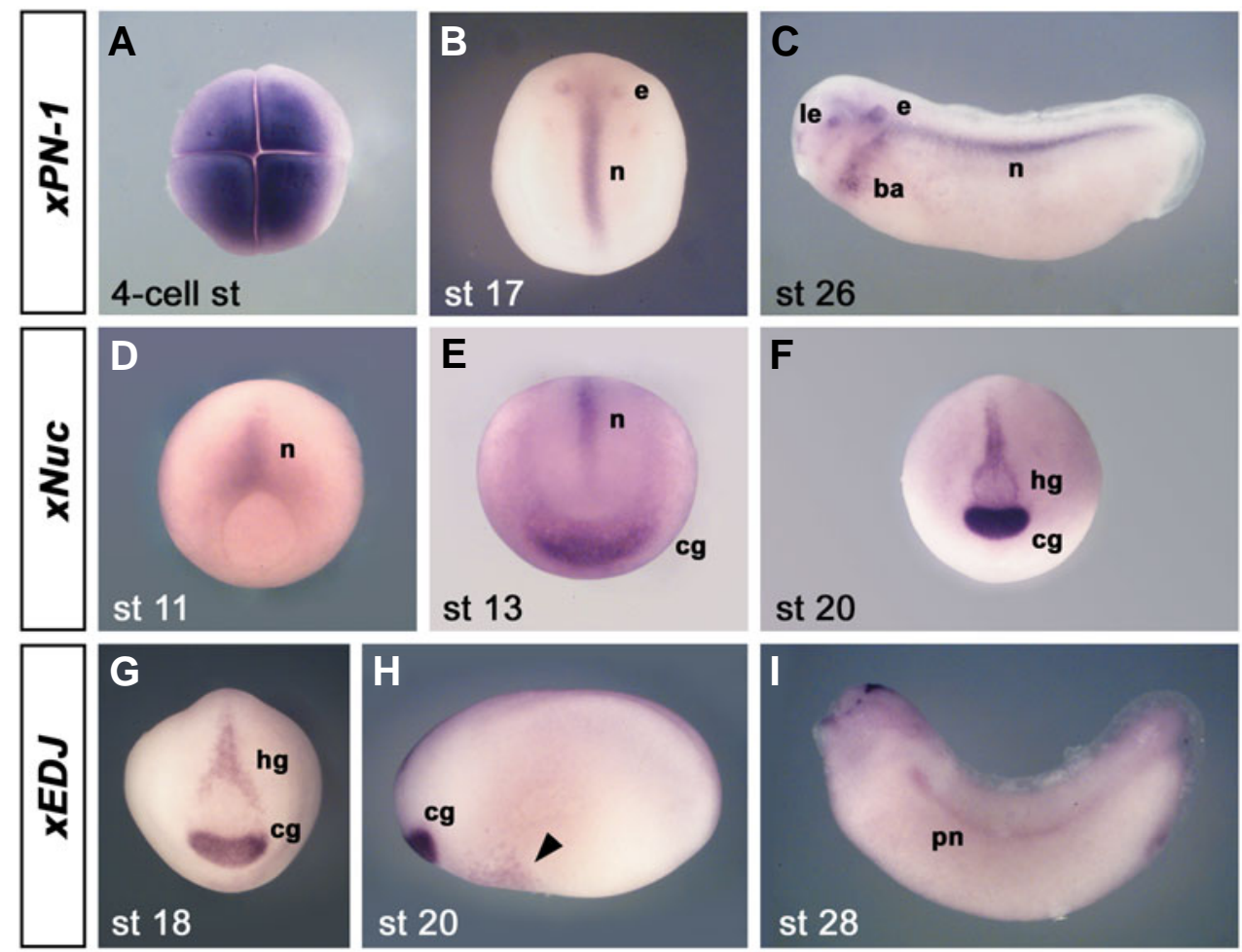

Fig. 6. Whole-mount in situ hybridization of xPN-1, xNuc and xEDJ. Embryos are shown in animal (A), dorsal $(B, D)$, lateral $(C, H, I)$ or anterior view (E-G). (A-C) Xenopus Proteinase Nexin-1 (xPN-1). (A) Four-cell stage embryo showing high level of maternal transcripts. (B) Late neurula. Note expression in the notochord (n) and ear placode (e). (C) Early tail bud stage with additional expression domains in the lens (le) and ectoderm of the branchial arches (ba). (D-F) Xenopus Nucleobindin (xNuc). (D) Midgastrula showing expression in the notochord (n). (E) Early neurula with additional signal in the cement gland (cg). (F) Late neurula. Note strong expression in the cement gland and hatching gland (hg). (G-I) Xenopus ER-associated DNAJ chaperone (xEDJ). (G) Late neurula with expression in cement gland (cg) and hatching gland (hg). (H) Late neurula depicting faint signal on the ventral side (arrowhead). (I) Early tail bud stage. Note expression in the pronephros (pn) and in the hatching gland in the dorsal head. pus development by whole-mount in situ hybridization. A strong signal was detected at the 4-cell stage, indicating abundant maternal transcripts (Fig. 3E). From neurula stage onwards, we found spotted expression in the epidermis (Fig. 3F). At tail bud stage, an additional expression domain appeared in the pronephros anlage (Fig. 3G). The spotted expression pattern of $x$ Gra2 is similar to that of $\alpha$-Tubulin, which demarcates ciliated cells in the epidermis and is regulated by Notch-signaling (Deblandre et al., 1999).

\section{Xenopus SOUL is a novel secreted protein}

We identified a new member of the SOUL/heme-binding protein (HBP) family, designated xSOUL (Fig. 4). The name was given due to sequence similarities to chick SOUL, which has expression in the pineal gland, the organ René Descartes hypothesized was the location of the soul (Zylka and Reppert, 1999). We found five isolates of XSOUL with a molecular weight of $23 \mathrm{kD}$ in the maternal and dorsal gastrula stage cDNA libraries (Table 3, Fig. 4A). Partial sequencing revealed that these clones represent at least three distinct pseudoalleles with significant differences in the 5'UTR (data not shown). One cDNA clone selected for fulllength sequencing encodes a protein of 208 amino acids. Data base comparisons showed related proteins in human, mouse, zebrafish, chick and plants (Fig. 4B). The Xenopus protein is highly divergent, since the closest relative was the SOUL-related protein from Arabidopsis (35\% amino acid identity). It is of interest to note that only Xenopus and Arabidopsis SOUL contained cleavable signal peptides (Fig. 4C). Indeed, the mouse SOUL and HBP proteins were found to be cytoplasmic (Zylka and Reppert, 1999). This suggests that the new Xenopus homolog may be unique among vertebrate SOUL/HBP proteins in participating in the secretory pathway. Like other members of this family, xSOUL showed a conserved hydrophobic region, which may be involved in binding of heme or other porphyrin compounds (Zylka and Reppert, 1999). By whole-mount in situ hybridization, we detected abundant maternal transcripts of $x S O U L$ at the 4-cell stage (Fig. 4D). At late neurula, weak expression was restricted to the midbrain and the posterior part of the forebrain (Fig. 4E). At tail bud stage, multiple expression domains were apparent in the brain, facial mesenchyme, lens, somites and particularly in the gut (Fig. 4F).

\section{A novel cysteine proteinase inhibitor: Xystatin}

We identified a new cysteine proteinase inhibitor protein of the cystatin superfamily, designated Xystatin. Xystatin (from Xenopus cystatin) was found as an $18 \mathrm{kD}$ protein in the supernatant of 
transfected 293T cells (Fig. 5A). Sequence comparison showed that Xystatin is distantly related to cystatin proteins in other vertebrates (Fig. 5B). The full-length cDNA clone encodes a 133 amino acid protein containing an amino-terminal signal peptide typical for secreted proteins (Fig. 5C). The mature protein (115 amino acids) is most homologous to Japanese quail egg white cystatin (38\% identity; Brown and Dziegielewska, 1997). Xystatin shares the basic structure of cystatin family members, including the active site $\mathrm{QxV} \times \mathrm{x}$ sequence, a conserved Pro-Trp (PW) sequence and four conserved cysteine residues crucial for the formation of two disulphide loops, making it likely that Xystatin is a functional cysteine protease inhibitor. By whole-mount in situ hybridization, we detected maternal transcripts at the 4-cell stage and ubiquitous expression at the gastrula and neurula stage; in tailbud embryos, Xystatin mRNA was restricted to the neural tube and neural crest cells in the anterior head and branchial arches (data not shown).

\section{Expression of additional genes identified by secretion clon- ing}

\section{Xenopus Protease Nexin-1}

Protease Nexin-1 (PN-1) is a serine protease inhibitor of the serpin family (Patston et al., 2004), which so far has only been cloned in amniotes. Embryonic expression has been reported for mouse (Küry etal., 1997) and chick (Rodríguez-Niedenführ et al., 2003) development. In Xenopus, PN-1 is abundantly expressed at the 4-cell stage as maternal mRNA (Fig. 6A). At neurula stage, distinct expression can be detected in the notochord and the otic placodes (Fig. 6B). At tail bud stage, additional expression is seen in the branchial arches, the midbrain-hindbrain boundary (MHB) and the lens (Fig. $6 \mathrm{C}$ ). In the mouse, it has recently been shown that the MHB expression of $P N-1$ is activated by FGF signaling (Küry et al., 1997). Since $P N-1$ shares several expression domains with $F G F 8$, including the notochord, otic placodes, branchial arches and the MHB, it is possible that $P N-1$ may belong to the FGF8 synexpression group (Niehrs and Meinhardt, 2002).

\section{Xenopus Nucleobindin}

Nucleobindin (Nuc) and the related NEFA protein (DNA binding/ EF-hand/acidic amino acid rich region) contain a signal peptide for secretion, a region rich in basic amino acids that is presumably a DNA-binding motif, two EF-hand motifs involved in calcium-binding and a leucine-zipper motif that is a dimerization domain (Otte et al., 1999; Lavoie et al., 2002). Although they have been reported to be involved in autoimmunity, apoptosis and calcium homeostasis in the Golgi apparatus and bone matrix, their exact role remains unknown. Xenopus Nuc shows dynamic expression during early development. During gastrulation, we detected transcripts at the dorsal blastopore lip and the embryonic midline (Fig. 6D). At the neural plate stage, expression was maintained along the dorsal midline and a new domain arose anteriorly in the cement gland primordium (Fig. 6E). We also detected weak staining in the epidermis. With the closure of the neural tube, strong signals were restricted to the cement gland and hatching gland (Fig. 6F). Interestingly, the Drosophila homolog nucb1 shows distinct expression in the salivary glands and their placodes (Otte et al., 1999), suggesting that the NEFA- nucleobindin class of calcium-binding EF hand proteins may have an evolutionarily conserved function in secretory gland tissues.

\section{Xenopus EDJ}

We identified the Xenopus homolog of the ER-associated DNAJ (EDJ) protein. EDJ is a member of the heat shock protein 40 (Hsp40) family that acts as a molecular chaperone in the lumen of the endoplasmic reticulum and as such is involved in translocation and degradation of misfolded proteins (Yu et al., 2000). By whole-mount in situ hybridization, we detected abundant maternal RNA of Xenopus EDJ (XEDJ) at the 4-cell stage and ubiquitous expression at the gastrula stage (data not shown). At late neurula stage, $X E D J$ transcripts were restricted to the anterior cement gland and hatching gland anlage (Fig. 6G). When the embryo started to elongate, further expression appeared ventrally in the area of the liver (Fig. $6 \mathrm{H}$ ). At advanced tailbud stage, an additional expression domain was found in the pronephros (Fig. 6I).

\section{Discussion}

To gain a more comprehensive understanding of intercellular signaling events, we set out to explore the molecular composition of the extracellular space in the early frog embryo. We developed a new technique to directly isolate secreted proteins as full-length cDNA clones. Our secretion cloning method was without bias, i.e., proteins were detected merely by the fact that they were secreted

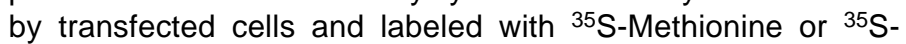
Cysteine. This retrieval of proteins irrespective of their function allowed us to identify new signaling proteins. By screening three expression cDNA libraries from early Xenopus embryos, we could isolate 170 positive clones. Among them, 51 encoded bona fide secreted proteins that were previously characterized in Xenopus or other vertebrates. Another 14 clones encoded novel secreted proteins. The results demonstrate that secretion cloning is a fruitful approach that provides an important method to investigate cell-cell communication during development.

\section{Secretion cloning provides a direct way to isolate secreted proteins}

Previous screens for secreted proteins were primarily directed at the presence of an amino-terminal signal peptide that allows the entry of the protein into the secretory pathway (Klein et al., 1996; Skarnes et al., 1995; Tashiro et al., 1999). In these signal sequence trap approaches, cDNA fragments provide a signal peptide to a carboxy-terminally fused protein. A mayor caveat of this screening technique was that the isolated cDNA clones were only partial. Our secretion cloning approach offers the advantage that secreted proteins are synthesized as full-length under native conditions, thereby preserving their structural integrity. The selection for full-length cDNA clones could be explained by the quality-control system in the endoplasmic reticulum, which, proofreads' newly synthesized proteins and targets misfolded proteins to degradation (Ellgaard and Helenius, 2003). Truncated proteins may not acquire the correctly folded conformation because of improper disulphide bond formation or glycosylation and hence fail to be secreted. Since we harvested proteins from the medium of transfected cells, no transmembrane proteins should be detected, which indeed was the case. The absence of plasma 
membrane proteins is in striking contrast to previous signal peptide screens, which targeted both secreted and transmembrane proteins. However, we could not prevent picking clones encoding lysosomal, ER and Golgi proteins (Fig. 2, Tables 1 and 2 ), probably due to the fact that the overexpression of proteins in transfected cells over-saturated the secretory pathway compartments, thus leading to an artificial release into the medium. Release of lysosomal proteins into the supernatant is a common phenomenon in cell culture and triggered for instance by $\mathrm{pH}$ changes in the medium (Hasilik, 1992). Lysosomal, ER and Golgi proteins have also been trapped by previous signal peptide screens (Klein et al., 1996; Skarnes et al., 1995; Tashiro et al., 1999).

Many extracellular signaling factors have cysteine-rich domains. Due to the non-reducing milieu in the secretory pathway compartments, covalent disulphide bridges can form before the proteins are released into the extracellular space. Intramolecular disulphide bridges are characteristic of the cystine knot, a structural motif that is frequently found in extracellular proteins (De Robertis and Kuroda, 2004). In our screen, the identification of cystine knot-containing proteins was facilitated through their incorporation of exogeneously added ${ }^{35}$ S-Cysteine during metabolic labeling. Examples of proteins with a cystine knot motif isolated by secretion cloning are Noggin, Cerberus and members of the TGF $\beta$ superfamily (Table 1 ). In addition, the two novel members of the Granulin family contain multiple copies of the socalled Granulin repeat characterized by twelve regularly spaced cysteine residues (Fig. 3). We note that cysteine-rich domains of the type present in Chordin (CR repeats) were not isolated. These modules bind members of the TGF $\beta$ and BMP family (Larraín et al., 2000) and are subjected to regulation by metalloprotease degradation.

Growth factors are normally not freely diffusible but rather bind to the cell surface or extracellular matrix. Recent studies in Drosophila and vertebrates have elucidated a crucial role for heparan sulphate proteoglycans (HSPGs) in regulating the distribution of these signaling molecules (Lin, 2004). HSPGs are cellsurface and extracellular matrix molecules composed of a core protein with covalently linked glycosaminoglycan (GAG) chains. The HSPGs interact with members of the Wnt, Hedgehog, TGF $\beta$ and FGF family and their GAG chains are of particular importance for the binding to the ligands. In order to compete with this binding and release growth factors, we added Heparin (a mixture of soluble heparan sulphate GAG chains) to the culture medium. However, only few growth factors were isolated in our screen, including three known members of the TGF $\beta$ superfamily (Nodalrelated-3, Antivin/Lefty, ADMP; Table 1) and the two novel Granulin proteins (Table 3). Despite the large number of cDNA clones screened, many other growth factors normally expressed at the analyzed stages escaped our detection, suggesting that addition of Heparin was not sufficient to release them into the medium. Cell surface and extracellular matrix proteins other than HSPGs may bind these growth factors and restrict their diffusion.

\section{Low yield of secreted proteins in Xenopus embryos at the 32- cell stage}

Relatively little is known about cell-cell signaling during the first hours of development, when no transcription occurs and all proteins are synthesized from maternal mRNA deposited in the egg. Despite some progress in recent years, the signals and pathways involved are only partially understood (De Robertis et al., 2000). Given that more than twenty-five thousand cDNA clones of the 32-cell stage cDNA library were screened, surprisingly few extracellular proteins with known signaling function were isolated. Among the growth factor antagonists, the only protein we found was Sizzled (Salic et al., 1997; Table 1). Other proteins previously reported to be secreted and not yet known in Xenopus included the calcium-binding EF-hand protein Nucleobindin and the translationally controlled tumor protein (TCTP; Table 2). In the unamplified maternal library, we isolated TCTP independently as three different cDNA clones suggesting a high abundance of this gene product in the Xenopus egg. A function for Sizzled, Nucleobindin and TCTP at this early stage of development remains to be shown. In addition, we identified the novel secreted proteins LAMA-like, SOUL and Darmin-related (Table 3). Their function remains to be determined. The relatively low yield of secreted signaling proteins suggest that cell-cell communication may not play a major role before mid blastula transition (MBT). It has previously been shown that pre-MBT cell contacts are dispensable for the expression of endodermal and dorsal mesodermal markers (Wylie et al., 1996; Yasuo and Lemaire, 1999). Thus, our data support the notion that early development up to MBT relies more on cell-autonomous signals rather than communications exchanged between cells.

\section{A large variety of signals present at the gastrula stage}

The complexity of signals identified rises by the time the embryo undergoes gastrulation. Concomitant with the formation of the three germ layers, cells constantly change their position with respect to each other, while exchanging messages. These intense cell and tissue interactions drive morphogenetic movements and pattern formation in the early embryo. To learn more about the signaling molecules involved, we screened two midgastrula stage libraries, one from embryos ventralized by UV exposure and the other from embryos dorsalized by $\mathrm{LiCl}$ treatment. We identified a wide spectrum of proteins acting at various levels in the regulation of growth factor signaling. Among the secreted proteins previously characterized in Xenopus or other vertebrates, 23 unique sequences were found (Tables 1 and 2). The list comprises one putative growth factor that signals through its own receptor (ADMP), ten soluble modulators that bind to growth factors or their receptors, one serine protease (HtrA1), one serine protease inhibitor ( $\mathrm{PN}-1)$, five protein-modifying enzymes (including the glycosyltranferase Lunatic Fringe), four proteins of the extracellular matrix (among them the co-receptor Glypican-4) and one protein with transport function (Ferritin $\mathrm{H}$ ). The majority of these proteins have well-established roles in the control of growth factor signaling in the extracellular space. In addition, we identified eight novel secreted proteins from gastrula-stage embryos (Table 3), including two members of the Granulin/Epithelin family of growth factors (xGra-1 and xGra-2), the metalloprotease Darmin, two putative proteinase inhibitors (Xystatin, Trinein) and proteins of unknown function, such as Isthmin, SOUL and ARMET. It will be interesting to determine their role during gastrulation. Our prelimary studies indicate that the secreted serine protease HtrA1 has important patterning activities in the Xenopus embryo (S. H. and E. M. P., data not shown). The serine protease inhibitor Trinein is also active in early devel- 
opment (O.W., José Garcia-Abreu, E. M. P. and E. M. D. R., data not shown). Thus cell-cell signaling is not restricted to growth factors and their receptors, but requires an intricate network of cofactors that orchestrate their activity in the extracellular space.

\section{The Spemann-Mangold organizer is a source of secreted antagonists}

Our study strongly supports the notion that the SpemannMangold organizer is a source of secreted growth factor antagonists. Upon LiCl-treatment, which expands the Spemann-Mangold organizer tissue and dorsalizes the embryos, several antagonists were identified (Table 1 and 2). The isolated factors mediate different functions of the Spemann-Mangold organizer and thereby affect pattern formation and morphogenesis of the embryo. BMP antagonists such as Noggin and $X \mathrm{nr} 3$ act as direct neural inducers and exert dorsalizing activity (Zimmerman etal., 1996; Hansen et al., 1997). The Wnt antagonists Frzb-1, sFRP-2 and Cerberus along with the pro-IGF signal IGFBP5 stimulate head development (Leyns et al., 1997; Piccolo et al., 1999; Pera and De Robertis, 2000; Pera etal., 2001). In contrast, the putative growth factor ADMP, isolated from LiCl-treated libraries, functions in the trunk organizer and antagonizes head formation (Moos et al., 1995; Dosch and Niehrs, 2000). Antivin/Lefty is involved in determining the left-right axis (Cheng et al., 2000). Finally, three factors regulate convergent-extension movements, i.e. Crescent and Glypican-4 possibly through inhibition of non-canonical Wnt ligands (Pera and De Robertis, 2000; Ohkawara et al., 2003) and Xnr3 via the FGF type 1 receptor (Yokota et al., 2003). Taken together, our data indicates that growth factor antagonism plays an important role in the organizing centre responsible for the establishment of the vertebrate body plan.

\section{Do lysosomal proteins act in the extracellular space?}

Although lysosomal enzymes usually segregate from other secretory proteins in the Golgi apparatus, where they are bound by mannose-6-phosphate receptors and directly routed to the lysosomes, the same receptors may localize to the plasma membrane in order to internalize extracellular lysosomal enzymes through endocytosis (Dahms et al., 1989; Neufeld, 1991). Lysosomal enzymes are generally synthesized as pre-pro-polypeptides and only when they reach the lysosomes they are processed into mature proteins. In our screen, all lysosomal proteins isolated in the supernatant of transfected 239T cells, including Cathepsin $B, L$ and $D$, Prosaposin, $\alpha$-Mannosidase and $\beta$-Hexosaminidase $\mathrm{B}$, were detected with a molecular weight corresponding to their precursor forms (data not shown), suggesting that they have never entered the lysosome prior to their release to the extracellular environment. Interestingly, all lysosomal enzymes identified by secretion cloning were heavily enriched in the conditioned medium (data not shown) and Cathepsins were the prevalent group of proteins isolated in our screen (with Cathepsin L reoccuring nineteen times; Table 2). These findings suggest that lysosomal proteins may not only act in lysosomes, but also fulfill an independent role in the extracellular space. Indeed, secreted lysosomal enzymes are crucial for tissue and bone remodeling during development (Dahms et al., 1989). Prosaposin, the precursor of four glycoprotein activators (termed saposins A-D) with glycosphingolipid hydrolase activity, has been identified as a neurotrophic factor capable of inducing neural differentiation and preventing cell death in mammals (O'Brien et al., 1994). It will be interesting to determine whether the lysosomal enzymes isolated by secretion cloning fulfill an extracellular function in Xenopus.

\section{Secreted proteins as potential targets for therapeutic drugs}

In the past, several large-scale efforts have been undertaken to identify new extracellular proteins. The Secreted Protein Discovery Initiative (SPDI) for example used various biological and computational approaches, including the signal sequence trap method in yeast, algorithms for signal sequence prediction and homology-based strategies, to screen for secreted and transmembrane proteins in humans (Clark et al., 2003). Our secretion cloning method complements these efforts and provides a new entry point to further isolate secreted proteins. Although applied here for Xenopus, our technique can be used to mine cDNA libraries of any source. In this way, large-scale screens for secreted proteins not only improve our understanding of intercellular communication, but also may lead to new understanding of human diseases and offer possible ways for the development of therapeutic cures. Secreted proteins in particular have properties that lend themselves to be utilized as therapeutic agents or targets. They are accessible to various drug delivery mechanisms, because they are presented within the extracellular space. A purified secreted protein can be utilized directly as a therapeutic, or may be targeted by specific antibodies or small molecules. The novel Xenopus proteins that have been identified by secretion cloning and described in this study await further characterization. We note that the early frog embryo provides a practical experimental system to investigate their activity and biological role.

\section{Materials and Methods}

\section{cDNA library construction}

Three plasmid libraries were screened, in which oligo dT primed cDNAs were cloned unidirectionally into cytomegalovirus (CMV) promoter-based expression vectors. An unamplified library from Xenopus UV-ventralized stage 11 embryos in the pcDNA3 vector and TOP10F' bacteria (Invitrogen) was generously provided by Dr. L. Zon (Boston). Two unamplified libraries from Xenopus stage 6 and LiCl-dorsalized stage 11 embryos were prepared by inserting cDNA into the Eco RI and $X$ hol sites of the pCS2+ vector (a gift of D. Turner) and transforming the clones into XLBlueMRF' bacteria (Stratagene).

\section{Secretion cloning method}

Bacterial colonies were manually picked from agar plates and inoculated in $1 \mathrm{ml}$ Terrific-broth/Ampicillin in 96-well blocks (Corning Costar, Cat. -No. 431139). The 96-well plates were covered with Parafilm and shaken for about 24 hours at $37^{\circ} \mathrm{C}$ and $200 \mathrm{rpm}$ in a humidified incubator. Aliquots from the media of 16 clones (125 $\mu \mathrm{l}$ each) were pooled and plasmid DNA extracted by Miniprep (Qiagen). Human embryonic kidney 293 T cells (ATCC) were cultured in 24-well plates using DMEM and 10\% fetal calf serum. At $50-70 \%$ confluence, $12.5 \mu \mathrm{M}$ chloroquine was added to inhibit degradation of transfected DNA by lysosomal hydrolysases. The cells were transfected with $2 \mu \mathrm{g} / \mathrm{ml}$ plasmid DNA and $0.2 \mu \mathrm{g}$ pAdvantage DNA (Promega) using the calcium phosphate method. After 36 hours, the cells were labeled with $110 \mu \mathrm{Ci} / \mathrm{ml}^{35} \mathrm{~S}$-Methionine and ${ }^{35} \mathrm{~S}$-Cysteine (Easy Tag Express ${ }^{35}$ S protein labeling mix, NEN) in serum-free medium. Heparin $(50 \mu \mathrm{g} / \mathrm{ml})$ was added to facilitate the release of secreted proteins from the cell surface. After 36 hours, the medium was harvested in microfuge tubes and cleared from cells by centrifugation at $800 \mathrm{~g}$ for 10 $\min$ at $4^{\circ} \mathrm{C}$. An aliquot of the medium was loaded onto a precast $4-20 \%$ 
gradient SDS polyacrylamide gel (Biorad) and electrophoresed under reducing conditions. The gels were fixed in 10\% acetic acid and 30\% glycerol for $15 \mathrm{~min}$, dried and exposed to a phosphor screen (Molecular Dynamics) or X-OMAT (AR) film (Kodak).

\section{Sib selection and gene identification}

Positive clones were individualized in a second step by sib selection. The 16 clones from each positive pool were regrown in a matrix of 4 rows and 4 columns in 96 -well arrays. Media from each row and column of the 96-well block were subpooled, plasmid DNA prepared and retransfected. If two subpools of one row and one column generated proteins of the same size as that of the original pool, a positive clone was identified. The selection was validated in a third round of transfection using the individual plasmid DNA. Partial gene sequence of the positive clones was obtained using automated sequencing. Approximately $500 \mathrm{bp}$ of 5 ' sequence (and eventually 3' sequence) was used to perform BLAST searches of the NCBI nucleotide and protein databases. Names were assigned to the cDNA clones according to the name of the gene with the best hit.

\section{RNA in situ analysis}

Whole-mount in situ hybridization was performed as described (http:/ /www.lifesci.ucla.edu/hhmi/derobertis/index.html). For antisense RNA probes, the pcDNA3 constructs of $X$ Gra-2 and $X P N-1$ were linearized with $B a m \mathrm{HI}$ and Hind III, respectively and transcribed with Sp6 RNA polymerase. The pCS2+ constructs of $x S O U L, X N U C$ and $x E D J$ were linearized with $B a m \mathrm{HI}$ and transcribed with T7 RNA polymerase.

\section{Acknowledgements}

We are indebted to Dr. L. Zon for the gift of the cDNA library. We thank Dr. T. Pielerfor his generous support and critically reviewing the manuscript and Dr. A. Hasilik for comments. We wish to thank S. L. Martinez, J. J. Flanagan, M. Brechner, L. Dornbach, C. Fields, A. Cuellar, D. Geissert, U. Tran, S. -Y. Li, I. Wunderlich and A. Nolte for excellent assistance. E.M.P. and O.W. were fellows of the Human Frontier Science Program Organization (HFSPO), E.M.P. was supported by a postdoctoral fellowship of the Deutsche Forschungsgemeinschaft (DFG) and S. H. is a Lichtenberg fellow of the International Master's/PhD Molecular Biology Program. The work was supported by NIH grant R37 HD21502-19 to E.M.D.R. and by a DFG grant PE 728/3 and funds of the Center of Molecular Physiology of the Brain (CMPB) Göttingen to E.M.P. E.M.D.R. is an Investigator of the Howard Hughes Medical Institute.

\section{References}

ALATALOS.L., HALLEEN J.M., HENTUNENT.A., MONKKONEN J. and VAANANEN H.K. (2000). Rapid screening method for osteoclast differentiation in vitro that measures tartrate-resistant acid phosphatase $5 \mathrm{~b}$ activity secreted into the culture medium. Clin. Chem. 46: 1751-1754.

BARTZ R., BENZING C. and ULLRICH O. (2003). Reconstitution of vesicular transport to Rab11-positive recycling endosomes in vitro. Biochem. Biophys. Res. Commun. 312: 663-669.

BATEMAN A. and BENNETT H.P. (1998). Granulins: the structure and function of an emerging family of growth factors. J. Endocrinol. 158: 145-151.

BENDTSEN J.D., NIELSEN H., von HEIJNE G. and BRUNAK, S. (2004). Improved prediction of signal peptides: SignalP 3.0. J. Mol. Biol. 340: 783-795.

BHANDARI V., PALFREE R.G.E. and BATEMAN A. (1992). Isolation and sequence of the granulin precursor cDNA from human bone marrow reveals tandem cysteine-rich granulin domains. Proc. Natt. Acad. Sci. USA 89: 1715-1719.

BOMMER U.A. and THIELE B.J. (2004). The translationally controlled tumour protein (TCTP). Int. J. Biochem. Cell Biol. 36: 379-385.

BROWN W.M. and DZIEGIELEWSKA K.M. (1997). Friends and relations of the cystatin superfamily-new members and their evolution. Protein Sci. 6: 5-12.

BUBLITZ C. and STEAVENSON S. (1988). The pentose phosphate pathway in the endoplasmic reticulum. J. Biol. Chem. 263: 12849-12853.

BUKRINSKY M.I. (2002). Cyclophilins: unexpected messengers in intercellular com- munications. Trends Immunol. 23: 323-325.

CHANG B.Y., PEAVY T.R., WARDRIP N.J. and HEDRICK J.L. (2004). The Xenopus laevis cortical granule lectin: cDNA cloning, developmental expression and identification of the eglectin family of lectins. Comp. Biochem. Physiol. A. Mol. Integr. Physiol. 137: 115-129.

CHENG A.M., THISSE B., THISSE C. and WRIGHT C.V. (2000). The lefty-related factor Xatv acts as a feedback inhibitor of nodal signaling in mesoderm induction and L-R axis development in Xenopus. Development 127: 1049-1061.

CLARK H.F., GURNEY A.L., ABAYA E., BAKER K., BALDWIN D., et al. (2003). The secreted protein discovery initiative (SPDI), a large-scale effort to identify novel human secreted and transmembrane proteins: a bioinformatics assessment. Genome Res. 13: 2265-2270.

CLAUSEN T., SOUTHAN C. and EHRMANN M. (2002). The HtrA family of proteases: implications for protein composition and cell fate. Mol. Cell 10: 443-455.

COLLAVIN L. and KIRSCHNER M.W. (2003). The secreted Frizzled-related protein Sizzled functions as a negative feedback regulator of extreme ventral mesoderm. Development 130: 805-816.

DAFFORN T.R., DELLA M. and MILLER A.D. (2001). The molecular interactions of heat shock protein 47 (Hsp47) and their implications for collagen biosynthesis. J. Biol. Chem. 276: 49310-49319.

DAHMS N.M., LOBEL P. and KORNFELD S. (1989). Mannose 6-phosphate receptors and lysosomal enzyme targeting. J. Biol. Chem. 264: 12115-12118.

DEBLANDRE G.A., WETTSTEIN D.A., KOYANO-NAKAGAWA N. and KINTNER C. (1999) A two-step mechanism generates the spacing pattern of the ciliated cells in the skin of Xenopus embryos. Development 126: 4715-4728.

DE ROBERTIS E.M., LARRAIN J., OELGESCHLÄGER M. and WESSELYO. (2000). The establishment of Spemann's organizer and patterning of the vertebrate embryo. Nat. Rev. Genet. 1: 171-181.

DE ROBERTIS E.M. and KURODA H. (2004). Dorsal-ventral patterning and neural induction in Xenopus embryos. Annu. Rev. Cell Dev. Biol. 20: 285-308.

DOSCH R. and NIEHRS C. (2000). Requirement for anti-dorsalizing morphogenetic protein in organizer patterning. Mech. Dev. 90: 195-203.

ELLGAARD L. and HELENIUS A. (2003). Quality control in the endoplasmic reticulum. Nature Rev. Mol. Cell Biol. 4: 181-191.

GALLI A., ROURE A., ZELLER R. and DONO R. (2003). Glypican 4 modulates FGF signalling and regulates dorsoventral forebrain patterning in Xenopus embryos. Development 130: 4919-4929.

GHOSH S., HEVI S. and CHUCK S.L. (2004). Regulated secretion of glycosylated human ferritin from hepatocytes. Blood 103: 2369-2376.

HANSEN, C. S., MARION, C. D., STEELE, K., GEORGE, S. and SMITH, W. C. (1997). Direct neural induction and selective inhibition of mesoderm and epidermis inducers by Xnr3. Development 124: 483-492.

HASILIK A. (1992). The early and late processing of lysosomal enzymes: proteolysis and compartmentation. Experientia 48: 130-151.

HAURI H., APPENZELLER C., KUHN F. and NUFER O. (2000). Lectins and traffic in the secretory pathway. FEBS Letters 476: 32-37.

HOWARD T.L., STAUFFER D.R., DEGNIN C.R. and HOLLENBERG S.M. (2001), CHMP1 functions as a member of a newly defined family of vesicle trafficking proteins. J. Cel/ Sci. 114: 2395-2404

HSU D.R., ECONOMIDES A.N., WANG X., EIMON P.M. and HARLAND R.M. (1998) The Xenopus dorsalizing factor Gremlin identifies a novel family of secreted proteins that antagonize BMP activities. Mol. Cel/ 1: 673-683.

ISAKSSON A. and HULTBERG B. (1995). Serum beta-hexosaminidase isoenzymes are precursor forms. Scand. J. Clin. Lab. Invest. 55: 433-440.

JESSOP C.E., CHAKRAVARTHI S., WATKINS R.H. and BULLEID N.J. (2004). Oxidative protein folding in the mammalian endoplasmic reticulum. Biochem. Soc. Trans. 32: 655-658.

KATZ A.B. and TAICHMAN L.B. (1999). A partial catalog of proteins secreted by epidermal keratinocytes in culture. J. Invest. Dermatol. 112: 818-821.

KLEIN R.D., GU Q., GODDARD A. and ROSENTHAL A. (1996). Selection for genes encoding secreted proteins and receptors. Proc. Natl. Acad. Sci. USA. 93: 71087113.

KUBO H., KAWANO T., TSUBUKI S., KOTANI M., KAWASAKI H. and KAWASHIMA S. (2000). Egg envelope glycoprotein gp37 as a Xenopus homolog of mammalian ZP1, based on cDNA cloning. Dev. Growth Differ. 42: 419-427.

KÜRY P., SCHAEREN-WIEMERS N. and MONARD D. (1997). Protease nexin-1 is expressed at the mouse met-/mesencephalic junction and FGF signaling regulates its promoter activity in primary met-/mesencephalic cells. Development 124 : 
1251-1262.

LARRAÍN J., BACHILLER D., LU B., AGIUS E., PICCOLO S. and DE ROBERTIS E.M. (2000). BMP-binding modules in chordin: a model for signalling regulation in the extracellular space. Development 127: 821-830.

LAVOIE C., MEERLOO T., LIN P. and FARQUHAR M.G. (2002). Calnuc, an EF-hand $\mathrm{Ca}(2+)$-binding protein, is stored and processed in the Golgi and secreted by the constitutive-like pathway in AtT20 cells. Mol. Endocrinol. 16: 2462-2474.

LEYNS L., BOUWMEESTER T., KIM S.H., PICCOLO S. and DE ROBERTIS E.M. (1997). Frzb-1 is a secreted antagonist of Wnt signaling expressed in the Spemann organizer. Cell 88: 747-756.

LIN X. (2004). Functions of heparan sulfate proteoglycans in cell signaling during development. Development 131: 6009-6021.

MAIER T., STRATER N., SCHUETTE C.G., KLINGENSTEIN R., SANDHOFF K. and SAENGER W. (2003). The X-ray crystal structure of human beta-hexosaminidase B provides new insights into Sandhoff disease. J. Mol. Biol. 328: 669-681.

MCNAUGHT K.S., KAPUSTIN A., JACKSON T., JENGELLEY T.A., JNOBAPTISTE R., SHASHIDHARAN P., PERL D.P., PASIK P. and OLANOW C.W. (2004). Brainstem pathology in DYT1 primary torsion dystonia. Ann. Neurol. 56: 540-547.

MOLONEY D.J., PANIN V.M., JOHNSTON S.H., CHEN J., SHAO L., WILSON R., WANG Y., STANLEY P., IRVINE K.D., HALTIWANGER R.S. and VOGT T.F. (2000). Fringe is a glycosyltransferase that modifies Notch. Nature 406: 369-375.

MOOS M. J.R., WANG S. and KRINKS M. (1995). Anti-dorsalizing morphogenetic protein is a novel TGF-beta homolog expressed in the Spemann organizer. Development 121: 4293-4301.

MURATA J., LEE H.Y., CLAIR T., KRUTZSCH H.C., ARESTAD A.A., SOBEL M.E., LIOTTA L.A. and STRACKE M.L. (1994). cDNA cloning of the human tumor motility-stimulating protein, autotaxin, reveals a homology with phosphodiesterases. J. Biol. Chem. 269: 30479-30484.

NEUFELD E.F. (1991). Lysosomal storage diseases. Ann. Rev. Biochem. 60: 257280.

NIEHRS C. and MEINHARDT H. (2002). Modular feedback. Nature 417: 35-36.

O'BRIEN J.S., CARSON G.S., SEO H.C., HIRAIWA M. and KISHIMOTO Y. (1994). Identification of prosaposin as a neurotrophic factor. Proc. Natt. Acad. Sci. USA. 91: 9593-9596.

OHKAWARA B., YAMAMOTO T.S., TADA M. and UENO N. (2003). Role of glypican 4 in the regulation of convergent extension movements during gastrulation in Xenopus laevis. Development 130: 2129-2138.

OTTE S., BARNIKOL-WATANABE S., VORBRUGGEN G. and HILSCHMANN N. (1999). NUCB1, the Drosophila melanogaster homolog of the mammalian EFhand proteins NEFA and nucleobindin. Mech. Dev. 86: 155-158.

PARK, H.S., KIM, M., SHIM, S. and HAN, J.K. (1998). Identification and expression study of a Xenopus homologue of prenylated SNARE gene. Biochem. Biophys. Res. Commun. 248: 235-239.

PATSTON P.A., CHURCH F.C. and OLSON S.T. (2004). Serpin-ligand interactions. Methods 32: 93-109.

PERA E.M. and DE ROBERTIS E.M. (2000). A direct screen for secreted proteins in Xenopus embryos identifies distinct activities for the Wnt antagonists Crescent and Frzb-1. Mech. Dev. 96: 183-195.

PERA E.M., WESSELY O., LIS.-Y. and DE ROBERTIS E.M. (2001). Neural and head induction by insulin-like growth factor signals. Dev. Cell 1: 655-665.

PERA E.M., KIM J.I., MARTINEZ S.L., BRECHNER M., LI S.-Y., WESSELY O. and DE ROBERTIS E.M. (2002). Isthmin is a novel secreted protein expressed as part of the Fgf-8 synexpression group in the Xenopus midbrain-hindbrain organizer. Mech. Dev. 116: 169-172.

PERA E.M., MARTINEZ S.L., FLANAGAN J.J., BRECHNER M., WESSELY O. and DE ROBERTIS E.M. (2003). Darmin is a novel secreted protein expressed during endoderm development in Xenopus. Gene Expr. Patterns 3: 147-152.

PEREZ S.E. and STELLER H. (1996). Molecular and genetic analyses of lama, an evolutionarily conserved gene expressed in the precursors of the Drosophila first optic ganglion. Mech. Dev. 59: 11-27.

PETERS, J.M., WALSH, M.J. and FRANKE, W.W. (1990). An abundant and ubiquitous homo-oligomeric ring-shaped ATPase particle related to the putative vesicle fusion proteins Sec18p and NSF. EMBO J. 9: 1757-1767.

PICCOLO S., AGIUS E., LEYNS L., BHATTACHARYYA S., GRUNZ H., BOUWMEESTER T. and DE ROBERTIS E.M. (1999). The head inducer Cerberus is a multifunctional antagonist of Nodal, BMP and Wnt signals. Nature 397: 707710.
RODRIGUEZ-NIEDENFÜHR M., PROLS F. and CHRIST B. (2003). Temporal and spatial protease nexin 1 expression during chick development. Gene Expr. Patterns 3: 611-614.

ROSA, F., SARGENT, T.D., REBBERT, M.L., MICHAELS, G.S., JAMRICH, M., GRUNZ, H., JONAS, E., WINKLES, J.A. and DAWID, I.B. (1988). Accumulation and decay of DG42 gene products follow a gradient pattern during Xenopus embryogenesis. Dev. Biol. 129: 114-123.

SALIC A.N., KROLL K.L., EVANS L.M. and KIRSCHNER M.W. (1997). Sizzled: a secreted Xwnt8 antagonist expressed in the ventral marginal zone of Xenopus embryos. Development 124: 4739-4748.

SHRIDHAR V., RIVARD S., WANG X., SHRIDHAR R., PAISLEY C., MULLINS C., BEIRNAT L., DUGAN M., SARKAR F., MILLER O.J., VAITKEVICIUS V.K. and SMITHD.I. (1997). Mutations in the arginine-rich protein gene (ARP) in pancreatic cancer. Oncogene 14: 2213-2216.

SILES-LUCAS M., NUNES C.P., ZAHA A. and BREIJO M. (2000). The 14-3-3 protein is secreted by the adult worm of Echinococcus granulosus. Parasite Immunol. 22: 521-528.

SKARNES W.C., MOSS J.E., HURTLEY S.M. and BEDDINGTON R.S. (1995). Capturing genes encoding membrane and secreted proteins important for mouse development. Proc. Natt. Acad. Sci. USA. 92: 6592-6596.

SPEMANN H. and MANGOLD H. (1924). Induction of embryonic primordia by implantation of organizers from a different species. Roux's Arch. Entw. Mech. 100, 599-638. Reprinted and Transl. Int. J. Dev. Biol. 45: 13-38.

SUN H. and WOLFE J.H. (2001). Recent progress in lysosomal alpha-mannosidase and its deficiency. Exp. Mol. Med. 33: 1-7.

TASHIRO K., NAKAMURA T. and HONJO T. (1999). The signal sequence trap method. Methods Enzymol. 303: 479-495.

WESSELY O., AGIUS E., OELGESCHLÄGER M., PERA E.M. and DE ROBERTIS E.M. (2001). Neural induction in the absence of mesoderm: beta-catenin-dependent expression of secreted BMP antagonists at the blastula stage in Xenopus. Dev. Biol. 234: 161-173

WESSELY O., KIM J.I., GEISSERT D., TRAN U. and DE ROBERTIS E.M. (2004) Analysis of Spemann organizer formation in Xenopus embryos by cDNA macroarrays. Dev. Biol. 269: 552-566.

WU J.Y., WEN L., ZHANG W.J. and RAOY. (1996). The secreted product of Xenopus gene lunatic Fringe, a vertebrate signaling molecule. Science 273: 355-358.

WU B.X., CHEN Y., CHEN Y., FAN J., ROHRER B., CROUCH R.K. and MA J.X. (2002). Cloning and characterization of a novel all-trans retinol short-chain dehydrogenase/reductase from the RPE. Invest Ophthalmol. Vis. Sci. 43: 33653372.

WYLIE C., KOFRON M., PAYNE C. ANDERSON R., HOSOBUCHI M., JOSEPH E. and HEASMAN J. (1996). Maternal beta-catenin establishes a 'dorsal signal' in early Xenopus embryos. Development 122: 2987-2996.

YAMAMOTO K., HAMADA H., SHINKAI H., KOHNO Y., KOSEKI H. and AOE T. (2003). The KDEL receptor modulates the endoplasmic reticulum stress response through mitogen-activated protein kinase signaling cascades. J. Biol. Chem. 278 : 34525-34532.

YASUO H. and LEMAIRE P. (1999). A two-step model for the fate determination of presumptive endodermal blastomeres in Xenopus embryos. Curr. Biol. 9: 869879.

YOKOTA C., KOFRON M., ZUCK M., HOUSTON D.W., ISAACS H., ASASHIMA M., WYLIE C.C. and HEASMAN J. (2003). A novel role for a nodal-related protein; $\mathrm{Xnr} 3$ regulates convergent extension movements via the FGF receptor. Development 130: 2199-2212.

YU M., HASLAM R.H. and HASLAM D.B. (2000). HEDJ, an Hsp40 co-chaperone localized to the endoplasmic reticulum of human cells. J. Biol. Chem. 275: 2498424992.

ZIMMERMAN L.B., DE JESUS-ESCOBAR J.M. and HARLAND R.M. (1996). The Spemann organizer signal noggin binds and inactivates bone morphogenetic protein 4. Cell 86: 599-606.

ZYLKAM.J. and REPPERT S.M. (1999). Discovery of a putative heme-binding protein family (SOUL/HBP) by two-tissue suppression subtractive hybridization and database searches. Mol. Brain Res. 74: 175-181.

Received: March 2005

Reviewed by Referees: April 2005

Modified by Authors and Accepted for Publication: April 2005 